\title{
MUJER DISCAPACITADA, EMPLEO Y PROGRESO TECNOLÓGICO. POLIMORFOLOGÍA DE UN CONFLICTO SISTÉMICO*
}

\author{
Marina Fernández Ramírez \\ Profesora Titular de Derecho del Trabajo y de la Seguridad Social \\ Universidad de Málaga
}

\begin{abstract}
En la sociedad actual continúa existiendo un espacio de invisibilidad en torno a las mujeres con discapacidad reconocida. Sufren las mismas desigualdades que en épocas anteriores, pero con unos efectos, incluso, más negativos. Obstáculos en ámbitos diversos de la vida cotidiana, pero, sobre todo, en el acceso al empleo. A mayor abundamiento, los nuevos escenarios introducidos por la revolución digital y la industria 4.0 representan para ellas un riesgo exponencial de exclusión digital y ponen en jaque su plena integración laboral. Pese a la articulación de un marco jurídico garante de la igualdad formal, la pervivencia de discriminaciones significativas en el acceso al mercado de trabajo de este colectivo no cesa. Ello evidencia que las normas legales son insuficientes per se, de modo que, un fenómeno tan complejo debe abordarse adaptando las soluciones a las exigencias de una realidad profundamente cambiante como la actual.
\end{abstract}

In today's society there continues to be a space of invisibility around women with recognized disabilities, who suffer the same inequalities as in previous times, but with even more negative effects. Obstacles in various areas of daily life, but, above all, in access to employment. Furthermore, the new scenarios introduced by the digital revolution and Industry 4.0 represent for them an exponential risk of digital exclusion and put their full labour integration in check. Despite the articulation of a legal framework that guarantees formal equality, the persistence of significant discrimination in access to the labour market for this group does not cease. We understand that legal norms are insufficient per se, so that such a complex phenomenon must be approached from holistic, approaches adapting solutions to the demands of a profoundly changing reality like the current one.

\footnotetext{
* Esta obra se enmarca en el contexto de los siguientes proyectos de investigación:

- Proyecto de Investigación "Las nuevas tecnologías y el impacto en el ámbito laboral y de la seguridad social: el impacto socioeconómico de la economía digital", financiado por la Junta de Andalucía y la Unión Europea, con financiación con fondos FEDER, (Ref. UMA18-FEDERJA-028).

- Grupo de Investigación financiado por la Junta de Andalucía (PAIDI SEJ-347), "Políticas de Empleo, Igualdad e Inserción social”.
} 
Title: Disabled women, employment and technological progress. Polymorphology of a systemic conflict

IUSLabor 2/2021, ISSN 1699-2938, p. 128-169

DOI. 10.31009/IUSLabor.2021.i02.05

Fecha envío: 8.2.2021 | Fecha aceptación: 1.3.2021

Palabras clave: mujer, discapacidad, empleo, progreso tecnológico, discriminación, nuevos itinerarios.

Keywords: women, disability, employment, technological progress, discrimination, new itineraries.

\section{Sumario}

1. Cuestiones introductorias

2. Principales obstáculos en el acceso al empleo de las mujeres discapacitadas. Reflexiones críticas

3. La mujer discapacitada frente al desafío de un mercado de trabajo digitalizado

4. Nuevos itinerarios de las políticas públicas para afrontar el problema

4.1. El eje de actuación normativa de las políticas públicas en materia de discapacidad.

4.2. II Plan Integral de Acción de Mujeres con Discapacidad 2013-2016

4.3. La Estrategia Española de la Discapacidad 2016-2020

5. El papel de la negociación colectiva en la inserción laboral de las mujeres discapacitadas

6. Balance crítico y propuestas de lege ferenda

7. Bibliografía 


\section{Cuestiones introductorias}

De acuerdo con las distintas dimensiones dicotómicas desde las que se ha analizado tradicionalmente la discapacidad1, el paradigma o modelo social, centrado en la integración y en la inclusión, ha servido de fundamento para las luchas que han llevado a cabo las personas con discapacidad (en adelante, PCD), desde la década de los setenta del siglo pasado ${ }^{2}$. Precisamente, uno de los logros internacionales más importantes de estas luchas ha sido la aprobación de la Convención Internacional de los Derechos de las Personas con Discapacidad en el año 2006 (CIDPCD). Con todo, el rasgo individual presente en el discurso sobre la discapacidad puede hacer olvidar el rol que juega la sociedad en la situación de discriminación y exclusión de las PCD. Lo social se pone de manifiesto mediante dos ámbitos: la representación social de instituciones, principalmente públicas, y la sociedad en general ${ }^{3}$. Las instituciones, como responsables de la discriminación hacia las PCD, se manifiestan principalmente en los ámbitos educativos, de salud y de pensiones, pero, sobre todo y, señaladamente, en el laboral ${ }^{4}$.

Tan es así que, la integración laboral, representa la razón de ser fundamental de las políticas de discapacidad, siendo el empleo el principal elemento de participación en la vida pública contemporánea (y simbólicamente de la condición de ciudadanía plena) y, por ende, carecer o no acceder a éste, ha supuesto una vía de exclusión tradicional. Teniendo en cuenta que las PCD representan alrededor del 15\% de la población mundial, cifra que va en aumento, nada resulta baladí en la lucha de este colectivo. Una lucha iniciada tras la segunda guerra mundial ${ }^{5}$ y que, aunque orquestada desde flancos diversos, siempre ha mantenido la proa puesta hacia la vinculación del discapacitado con el mundo del trabajo. Empezando por su nomenclatura, que ha pasado de PCD a personas con diversidad funcional, terminología más actualizada ${ }^{6}$ que no sólo se adecúa mejor al perfil

\footnotetext{
${ }^{1}$ Cfr. Vergara HeIDKE, Adrián, "El discurso sobre la discapacidad: principales dimensiones dicotómicas”, Revista Latinoamericana de Estudios del Discurso, vol. 19, 2019, p. 94-110.

2 Palacios Rizzo, Agustina, El modelo social de discapacidad: orígenes, caracterización y plasmación en la Convención Internacional sobre los Derechos de las Personas con discapacidad, Madrid, Cinca, 2008, p. 103.

${ }^{3}$ Vergara HeIDKE, Adrián, "El discurso sobre la discapacidad...,", op. cit., p. 105.

${ }^{4}$ Cfr. Plan de Acción de la Estrategia Española sobre Discapacidad 2014-2020, p. 6 y ss.

${ }^{5}$ Vid. el artículo "Disability rights around the world: from 1944 to the present day", publicado por el diario The Guardian, en el que, a través de una infografía cronológica, hace un repaso de la lucha de los discapacitados por sus derechos sociales, laborales y jurídicos.

${ }^{6}$ Inspirada en la "Convención ONU sobre derechos [humanos] de las personas con discapacidad", que se basa en la pretendida conjugación de los derechos de dignidad y libertad de las personas con discapacidad/diversidad funcional. Vid. GonZÁLEZ RAMOS, Pilar, "Las Mujeres con discapacidad y sus múltiples desigualdades; un colectivo todavía invisibilizado en los Estados latinoamericanos y en las agencias de cooperación internacional". XIV Encuentro de Latinoamericanistas Españoles: Congreso internacional, 2010, Santiago de Compostela, España, p. 2741.
} 
de un grupo heterogéneo integrado por personas con deficiencia, discapacidad y minusvalía, sino que, sobre todo, invita a alejarnos de la visión tradicional, peyorativa y excluyente de la discapacidad entendida como déficit en la capacidad para realizar cualquier tarea o trabajo ${ }^{7}$. Sin empleo no hay integración ni participación social de los discapacitados. Por ello, las políticas de empleo para las PCD se han convertido en un aspecto nuclear de integración en la comunidad.

Aun así, los avances en este campo, pese a los indudables esfuerzos realizados, son insuficientes; y, si bien, hoy contamos con un conjunto de variables que identifican y permiten medir correctamente lo que significa inclusión laboral y social de PCD, y ha habido avances importantes en materia de acceso al empleo, otros aspectos tales como la permanencia del discapacitado en el trabajo, la conciliación, el derecho de sindicación, o el acceso a bienes, productos, servicios y entornos que ofrecen las empresas, siguen siendo un intangible en las políticas empresariales ${ }^{8}$. Los datos de empleo revelan la ausencia de una implementación del compromiso social y empresarial en favor de la integración ${ }^{9}$, un alto índice de paro y unos niveles de precariedad superiores a la media ${ }^{10}$. Laboralmente, pues, el impacto que sufren las PCD es doble y las variables que contribuyen a esta realidad, son múltiples. El tipo de discapacidad, el grado, él género, la pluridiscapacidad, o la inversión en capital humano influyen en la probabilidad de participar en el mercado de trabajo, ya sea de forma negativa o positiva ${ }^{11}$.

Ser mujer, representa además una agravante cualificada que multiplica per se las dificultades a las que se enfrentan los hombres discapacitados que quieren acceder al mercado de trabajo y/o mantenerse dentro. En la Declaración sobre el Reconocimiento de los Derechos de las niñas y mujeres con discapacidad de 2007, se denuncia: “Que, las niñas y mujeres con discapacidad siguen hoy en día enfrentándose a los efectos de una discriminación clara y rotunda". A pesar de los avances importantes obtenidos en los últimos años, este tipo de discriminación sigue representando un problema grave y

\footnotetext{
${ }^{7}$ Con todo, es un término cuya aceptación no acaba de ser pacífica. El Comité español de Representantes de Personas con Discapacidad (CERMI) sigue prefiriendo el término "discapacidad", ya que según la organización la "diversidad funcional" no identifica la realidad del colectivo y de su movimiento social, generando inseguridad jurídica, incluso a la hora de rebajar las medidas de protección que necesitan.

${ }^{8}$ Cfr.: Los derechos humanos de las personas con discapacidad: guía práctica para empresas, publicada por CERMI y Business and Human Rights (BHR), 2019.

${ }^{9}$ RiBes Moreno, María Isabel, "Cabe utilizar la negociación colectiva para integrar laboralmente a las personas con discapacidad. Una propuesta a la luz de la experiencia francesa", Lan Harremanak, $\mathrm{n}^{\circ} 35$, 2016, p. 360.

${ }^{10}$ Vid. ODISMET: 4 Informe del Observatorio sobre Discapacidad y Mercado de Trabajo de la Fundación ONCE, p. 20 y ss.

${ }^{11}$ Rodríguez Álvarez, Vanesa, CuETo IGLESIAS, Begoña, "El trabajo de las personas con discapacidad ante la crisis", Revista Internacional de Organizaciones, n ${ }^{\circ}$ 11, 2013, p. 6.
} 
alarmante. Los resultados muestran que, la mujer con discapacidad (en adelante, MCD), está doblemente discriminada. Por su condición de mujer y por su condición de discapacitada. Participa en menor medida en el mercado laboral, tiene mayores dificultades para permanecer en su puesto de trabajo y las condiciones asociadas a los puestos que ocupa, tanto en parcialidad como en retribución por igual trabajo, en las tasas de ascensos, en el acceso a actividades de capacitación y reciclaje profesional, en el crédito y otros recursos productivos, son peores que para sus compañeros varones discapacitados. Además, rara vez participan en los procesos de toma de decisiones económicas. Y las estimaciones de la probabilidad de contratación indefinida, es de tres puntos porcentuales superior para los hombres que para las mujeres dejando constancia de una mayor dificultad en mantener su estabilidad laboral.

Una realidad que pasa de poco halagüeña a muy preocupante cuando le agregamos el dato cuantitativo. Según el INE, en España hay casi tres millones de mujeres con alguna discapacidad, lo que supone un $60 \%$ de toda la población con discapacidad ${ }^{12}$. De hecho, el binomio mujer-discapacidad, no sólo afecta a la participación laboral sino a las condiciones en las que se desarrolla dicha participación. En suma, se demuestra que el mercado laboral es sexuado - pensado para los hombres - y, además, "capacista" pensado para los capaces ${ }^{13}$. En este penoso escenario, el desconocimiento y la falta de conciencia que muchas MCD tenían, y siguen teniendo, acerca de su propia identidad y subjetividad femenina, y el convencimiento profundo de que la lucha por los derechos de las mujeres era ajena, o a lo sumo, debía ser el objetivo de otros grupos sociales que nada tenían que ver con el de la discapacidad ${ }^{14}$, ha sido quizá el peor de los escollos a sortear, coadyuvando seriamente a la ralentización del reconocimiento de sus derechos y libertades fundamentales sociolaborales. Con lo cual, y con esta premisa de fondo, corroboramos que el mercado laboral del siglo XXI continúa planteando un sinfín de barreras a las MCD sin que, como se verá, el diagnóstico valorativo actual arroje variaciones sustanciales respecto al tipo de problemas detectados en el pasado ${ }^{15}$, aunque, ciertamente, hayan mejorado en su enfoque y resultados ${ }^{16}$.

\footnotetext{
${ }^{12}$ Instituto Nacional de Estadística (INE). Encuesta sobre Discapacidades, Deficiencias y estado de Salud. Avance de resaltados. Datos básicos. Subdirección General de Difusión Estadística e Instituto Nacional de Estadística (INE). Madrid, 2019. (Disponible en web: http://www.ine.es/inebase/cgi/um).

${ }^{13}$ SCUdieri, Laura, GuAglianone, Luciana, Escudero, Ricardo y CReSPo PuRAs, Carmen, Inclusión sociolaboral de las mujeres con discapacidad. Manual. RISEWISE-AFADIS-UCM, Madrid, España, 2019 (No publicado), p. 6.

${ }^{14}$ CERMI. La transversalidad de género en las politicas públicas de discapacidad, vol. II, 2013, p. 17.

${ }^{15} \mathrm{Cfr}$. a este respecto, CES: Sobre la situación del empleo de las personas con discapacidad y propuestas para su reactivación, Consejo Económico y Social no 4, Madrid, 1995, y CES, La situación del empleo de las personas con discapacidad en España, Consejo Económico y Social, nº 5, Madrid, 2003.

${ }^{16}$ Cfr. Mercado García, Esther, Aizpurúa González, Eva y García Vicente, Luis Mariano, "Avanzando hacia la igualdad de oportunidades en la inclusión sociolaboral de las personas con
} 
En el caso español el principal problema de las MCD, ha sido y es su baja participación laboral, como recoge el 5 Informe del Observatorio sobre Discapacidad y Mercado de Trabajo de la Fundación ONCE ${ }^{17}$, que las aboca a una situación de empobrecimiento y precariedad $^{18}$, y cercena todas las posibilidades de desarrollo de un proyecto de vida propio y de una plena participación en comunidad. Incluso se da la paradoja de que las actuales características contractuales impiden, en ciertos casos, que las MCD empleadas se sitúen fuera del umbral de la pobreza. Desde el punto de vista de la contratación, los contratos de las MCD suponen únicamente el 1,3\% de todos los contratos a mujeres realizados en España durante 2017, una cifra casi irrisoria que hace patente la grave dificultad del colectivo para acceder a un puesto de trabajo. Respecto a sus compañeros hombres, las MCD suponen el 38,4\% de las contrataciones a personas con diversidad funcional, brecha que evidencia la doble discriminación que sufren.

A la crudeza de lo descrito, y como significada novedad, se suma ahora la eclosión de la era digital en su versión negativa. El sector tecnológico continúa ganando cuota de mercado en el PIB mundial y hace que la tecnología tenga progresivamente un mayor calado en la vida de las personas, permitiéndoles el acceso a productos y servicios que suponen también una mayor eficiencia y el logro de progresos de desarrollo económico y social. En paralelo, y consecuencia de lo anterior, el trabajo, su contenido, su organización y su diseño, así como su normativa y su protección, están experimentando grandes transformaciones, que exigen para su adaptación cambios culturales y formativos de gran envergadura. El enfoque tradicional del trabajo como modelo a seguir, atendiendo a los nuevos escenarios introducidos por la revolución digital y la industria 4.0, se ha agotado para cualquier trabajador sin discapacidad y, a mayor abundamiento, para las PCD. Pensemos que esta realidad implica para ellas un riesgo exponencial de exclusión digital y laboral, considerando, además, la posible concurrencia simultánea o sucesiva en el mismo sujeto de otras variables habituales de exclusión, geográficas, culturales, generacionales, formativas, de discapacidad, o de género. Es la denominada brecha digital, abierta como un crisol si el afectado es mujer y, además, discapacitada, y en el que, la problemática que históricamente ha acompañado a la MCD en su acceso al empleo se funde ahora con el intrincado y emergente escollo tecnológico.

Sobre la premisa descrita, en este trabajo nos proponemos analizar los problemas polimórficos y las discriminaciones jurídicas a las que quedan expuestas las MCD, para incorporarse al mercado laboral en igualdad de condiciones que las mujeres no

discapacidad", Cuadernos de Trabajo Social, vol. 26-1, 2013, p. 95; Plan de Acción de la Estrategia Española sobre Discapacidad 2014-2020, p. 6 y ss.

${ }^{17}$ Según datos del 5 Informe General del Observatorio sobre Discapacidad y Mercado de trabajo en España (ODISMET), 1.245.200 personas con discapacidad en edad activa son inactivas laboralmente; p. 21.

${ }^{18}$ Casi tres de cada diez personas con discapacidad viven en riesgo de pobreza o exclusión social. 
discapacitadas. Primero, describiendo la realidad laboral de las MCD en España desde un enfoque esencialmente cuantitativo, valorativo y crítico. $\mathrm{Y}$, segundo, analizando el conjunto de medidas públicas y privadas, así como las políticas orientadas a la inserción laboral de las PCD, teniendo en cuenta que los poderes públicos deben incorporar acciones eficaces dirigidas a remover los obstáculos que impiden que la igualdad sea una realidad en nuestras sociedades. Por último, y a modo de balance final, se hacen una serie de propuestas de lege ferenda, en el intento de ofrecer algo de luz a lo que entendemos son los aspectos más nucleares de este conflicto sistémico.

\section{Principales obstáculos para el acceso al empleo de las mujeres discapacitadas. Reflexiones críticas}

Las PCD y, en especial, las MCD, como colectivo especialmente vulnerable, tienen derecho a ganarse la vida mediante un trabajo digno libremente elegido o aceptado en un mercado laboral que sea abierto, inclusivo y accesible. Es más, en las MCD, el papel central que ocupa el empleo es bastante más trascendente que para el resto, toda vez que, para ellas, no sólo supone obtener una remuneración, sino también otros beneficios entre los que se incluyen el refuerzo de su identidad personal y el hecho de ser un medio para estructurar y ocupar su tiempo, conseguir contactos sociales, responsabilidad y participación productiva y, finalmente, dar un sentido de logro personal a su vida ${ }^{19}$. De modo que, conseguir trabajo, es casi más beneficioso que cualquier otra intervención médica o social.

Es cierto que buena parte de la problemática que a continuación expondremos sobre el empleo y las MCD se puede extrapolar y aplicar a cualquier mujer; la diferencia estriba en la mayor dificultad de aquéllas para acceder al empleo y mantenerlo por su mayor exposición a los procesos desencadenantes de discriminación y, en consecuencia, a una situación, de partida, de clara desventaja respeto a las mujeres sin discapacidad ${ }^{20}$. Por lo tanto, el ejercicio de su derecho al trabajo debe salvaguardarse y promoverse, incluso para las mujeres a las que sobreviene una discapacidad durante el desarrollo del contrato. En esta línea avanza la Agenda 2030 y los Objetivos de Desarrollo Sostenible en tanto que defienden "Promover el crecimiento económico sostenido, inclusivo y sostenible, el

\footnotetext{
${ }^{19}$ BOARDMAN, Jed, GROVE, Bob, PERKINS, Rachel y SHEPHERD, Geoff, "Work and employment for people with psychiatric disabilities”, The British Journal of Psychiatry, 182 (6), 2003, p. 467 y 468.

${ }^{20}$ CARIACEDO PÉREZ, Lola., "Mujeres Jóvenes y nuevas tecnologías. Nuevas actrices y herramientas para una vieja deuda", en AGUINAGA Josune, (coord.), Revista de Estudios de Juventud, $\mathrm{n}^{\circ}$ 83. Mujeres jóvenes en el siglo XXI. INJUvE. Madrid. 2008, p. 166 y 167.
} 
empleo pleno y productivo y el trabajo decente para todas las personas" (ODS 8) y "Lograr la igualdad de género y empoderar a todas las mujeres y las niñas" (ODS 5) 21.

Sin embargo, la realidad actual nos muestra un panorama muy diferente de modo que, los índices de actividad, empleo y desempleo, así como las condiciones laborales, son peores en las MCD cuando las comparamos con los hombres con discapacidad y con las demás personas sin discapacidad. Complementariamente, la situación de alarma sanitaria que padecemos (COVID), y sus contundentes repercusiones en el empleo, han afectado de manera exponencial al colectivo de discapacitados ${ }^{22}$. En particular, a las MCD. De hecho, un 64\% de ellas, considera el acceso al empleo su mayor preocupación en la situación derivada de la COVID-19 ${ }^{23}$. Entre las razones, el miedo a la precarización de las condiciones laborales, la pérdida de empleo o encontrarse con mayores dificultades a la hora de acceder a un trabajo, sumándose la brecha digital para optar a puestos ofertados a través de internet.

Insistimos en que el trabajo sigue siendo una de las vías fundamentales que garantiza a las MCD la posibilidad de llevar una vida autónoma e independiente, y ser, de esta manera, protagonistas de sus propias vidas. Por tanto, la lectura al respecto es clara, y es que algo falla cuando estas mujeres en búsqueda activa de empleo se enfrentan en España, hoy por hoy, a la tiranía de un mercado de trabajo que les sigue planteando obstáculos tan variados y complejos de sortear como los siguientes:

- Discriminaciones laborales directamente vinculadas con el género y la discapacidad. Ser mujer y tener alguna discapacidad son variables que afectan de manera casi determinante a la probabilidad de participar en el mercado de trabajo. Se trata de una doble discriminación que reproduce las diferencias de género ya existentes en el mercado laboral global, destacando una menor participación femenina, aunque, en términos generales, con peores condiciones para las MCD, tanto en la incorporación, como en la evolución posterior de su trayectoria laboral ${ }^{24}$. Asimismo, no podemos obviar la perspectiva interseccional en la discriminación que sufren las MCD, es decir, la interacción simultánea de varias diferencias humanas según género, raza/etnia, clase, religión, orientación sexual, edad, capacidad, ciudadanía, identidad nacional, contexto geopolítico o condiciones de salud, toda vez

\footnotetext{
${ }^{21}$ Conviene señalar que, no obstante, estos objetivos no son jurídicamente obligatorios; su cumplimiento y su éxito se basan en las políticas, planes y programas de desarrollo sostenible de cada país.

22 Vid.: Informe de detección de necesidades de las mujeres con discapacidad. Impacto de la COVID-19, elaborado por la Confederación Española de Personas con Discapacidad Física y Orgánica (COCEMFE).

${ }^{23}$ Vid.: Informe de detección de necesidades de las mujeres con discapacidad..., op. cit.

${ }^{24}$ En el informe: Integración en el mercado laboral de mujeres con discapacidad atendiendo a su nivel de estudios, CNIIE e Instituto de la Mujer y para la Igualdad de Oportunidades, 2015, p. 15.
} 
que las sitúa en el plano de la discriminación múltiple y la máxima vulnerabilidad social y laboral ${ }^{25}$.

Grosso modo, durante el período 2008-2011, la tasa de actividad ha disminuido y la de paro ha aumentado, aunque se ven ciertas diferencias entre colectivos y género. En el año 2011, las mujeres tuvieron menor tasa de actividad y mayor tasa de paro que sus compañeros varones. Concretamente, la tasa de actividad de las mujeres fue del 33\% frente al 69,3\% de los hombres, mientras que la tasa de paro superó el $27 \%$ frente al 22,2\% de los hombres. En el caso de las MCD, y según datos de 2017, el último año del que el INE tiene información, los números no difieren tanto con los de los hombres de su misma condición. El $65 \%$ de ellas se encuentran inactivas a nivel laboral, y de las que se encuentran en activo, sólo trabaja el 25,6\%, frente al $26 \%$ en el caso de los hombres. Las cifras muestran que las mujeres no sólo tienen una menor tasa de participación en el mercado laboral, sino que, además, tienen mayores dificultades para permanecer en su puesto laboral y, cuando participan en el mismo, muestran mayores tasas de paro $^{26}$.

La tasa de inactividad de las MCD en España asciende al 64,8\%, una cifra superior a la de los hombres con discapacidad y mucho peor que la de la población sin discapacidad. Ello hace que muchas MCD en edad laboral no solo no tengan trabajo, sino que ni siquiera estén en el proceso de búsqueda. Asimismo, mostraría una importancia primaria de discriminación por discapacidad y la doble discriminación relacionada con la diferencia de género y, por tanto, podría tomarse como un apoyo para recomendar el mantenimiento y el refuerzo de las medidas de promoción de acceso de las mujeres en general ${ }^{27}$. Esa menor tasa de participación en el mercado laboral de las PCD se debe a factores individuales y factores sociológicos y, en el caso de las MCD, se trata de un fenómeno complejo que aúna dos condiciones, las cuales, de forma independiente, constituyen una causa en sí de baja participación. Por un lado, la menor tasa de actividad de las PCD, y por otro, las menores tasas de participación que presentan las mujeres. Es por ello que se habla de una doble discriminación: por ser mujer y por pertenecer al colectivo de discapacitados ${ }^{28}$.

\footnotetext{
25 BALLESTER CARDELL, María, "Mujer y discapacidad", en VVAA.: La discriminación múltiple en los ordenamientos jurídicos español y europeo, Rosario SERRA (Dir.), Valencia, Tirant lo Blanch, 2013, p. 6.

${ }^{26}$ Cfr. Integración en el mercado laboral de mujeres con discapacidad..., op. cit., p. 15.

27 DÁvila Quintana, Carmen Delia, Malo OCAÑA, Miguel Ángel, “Género, discapacidad y posición familiar: La participación laboral de las mujeres con discapacidad”, Cuadernos Aragoneses de Economía, 16 (1), 2006, p. 61-82.

${ }^{28}$ Para un estudio en profundidad, RuIZ CAstillo, María del Mar, Igualdad y no discriminación. La proyección sobre el tratamiento laboral de la discapacidad, ed. Bomarzo, 2010.
} 
La importancia de seguir apoyando a las MCD en su acceso al empleo es crucial, así como garantizar que su contratación no obedezca exclusivamente a la coyuntura del momento, sino que sea extensible y sostenible en cualquier ciclo económico. Pero, asimismo, es clara la contundente necesidad de que, en el desarrollo de las políticas y también en el propio despliegue normativo, se tenga en cuenta la perspectiva de género y, particularmente, la perspectiva de género transversal. Entendemos que, desde las políticas públicas de igualdad y empleo, no se han prestado suficientes apoyos a las discriminaciones múltiples, y que ha llegado el momento de sumar acciones positivas necesarias para apostar por el talento y la plena participación social de las $\mathrm{MCD}^{29}$, e incluir el enfoque de género de forma transversal en todas las actuaciones vinculadas a este objetivo ${ }^{30}$. Igualmente, es necesario que se atienda a un enfoque de la discapacidad no como un todo y de forma homogénea, pues se estaría contribuyendo a provocar discriminación, dado que existen tantos tipos de discapacidad como PCD. El análisis de las capacidades de los individuos -en este caso las mujeres- será fundamental para su inclusión en la sociedad y, como veremos, también a la hora de explicar su relación con las TIC ${ }^{31}$.

Todavía queda mucho por hacer en relación a la inserción laboral de las PCD, tanto en el ámbito interno español como en el europeo. Por ello, el presidente del Foro Europeo de la Discapacidad ha pedido a la nueva Comisión Europea que haga un seguimiento del proceso de implantación y desarrollo de la Directiva sobre Igualdad de Trato en el Puesto de Trabajo y de Ocupación ${ }^{32}$ y aumente la inversión a cargo de los fondos estructurales en acciones dirigidas a conseguir la inserción laboral de este colectivo. Asimismo, ha puesto de relieve la necesidad de una mayor vigilancia de las directivas existentes y aprobar más normas antidiscriminación de carácter horizontal. Lograr la igualdad de las MCD, el derecho a no ser discriminada y a la inclusión, debe ser complementado con el derecho a recibir apoyo y asistencia ${ }^{33}$, así como con la implementación de intervenciones institucionales y legales para evitar la discriminación y la exclusión social en un tratamiento holístico y transversal del problema. Implicaría la transformación de hábitos, actitudes y comportamientos,

\footnotetext{
${ }^{29}$ Sobre la importancia de las acciones positivas en las políticas de empleo, cfr. MARTín TRILLO, Patricia, "Análisis crítico de las políticas públicas de empleo en la Discapacidad y el Género", Documentos de trabajo social: Revista de trabajo y acción social, nº 60, 2017, p. 149.

${ }^{30}$ Cfr. La Transversalidad de Género en las Políticas Públicas de Discapacidad, vol. I, publicado por CERMI, 2012, p. 36 y 37.

${ }^{31}$ Gomiz PASCUAL, María Pilar, "TIC y mujeres con discapacidad una ventana al mundo", Revista de Estudios de Juventud, $\mathrm{n}^{\mathrm{o}}$ 111, 2016 (Ejemplar dedicado a: Jóvenes e identidades), p. 121.

${ }^{32}$ DIRECTIVA 2006/54/CE DEL PARLAMENTO EUROPEO V DEL CONSEJO, de 5 de julio de 2006 relativa a la aplicación del principio de igualdad de oportunidades e igualdad de trato entre hombres y mujeres en asuntos de empleo y ocupación. (DOCE L 204/23).

${ }^{33}$ Declaración de Madrid, 2002. (Disponible en: www.discapnet.es).
} 
fomento del empleo como factor clave para la inserción social, aseguramiento de la salud, aseguramiento frente a riesgos profesionales, sistema general de pensiones, apoyo especial a las mujeres y menores con discapacidad, apoyo a las familias, servicios que promuevan vida independiente, servicios de rehabilitación, barreras y prácticas institucionales, sector cultural comunicaciones, etc. La transversalidad en este ámbito (mainstreaming de género) ${ }^{34}$ es determinante, pues supone que las actuaciones que desarrollan las Administraciones Públicas no se limitan únicamente a programas específicos pensados exclusivamente para estas personas, sino que comprenden las políticas y líneas de acción de carácter general en cualquiera de los ámbitos de actuación pública, en donde se tendrán en cuenta las necesidades y demandas de las MCD.

- Prejuicios de las empresas a la contratación de discapacitados. Uno de los grandes retos que tienen las empresas públicas y privadas hoy en día es asumir que, además de tener una función económica o productiva tienen, también, una función y una dimensión de carácter social; una responsabilidad con los ciudadanos y con la sociedad con la que conviven. Una de estas acciones sociales, como bien ha definido la propia $\mathrm{OIT}^{35}$, consiste en llevar a cabo la integración de las PCD en el ámbito laboral como parte coadyuvante esencial a la integración social de las mismas. Ciertamente, la contratación de PCD se ha incrementado a un ritmo superior al general. En concreto, en estos 10 últimos años, ha aumentado un 109\% y mantiene su tendencia al alza anotando, en 2018, el mejor registro de toda la serie histórica con 116.873 contratos. Entre las causas que subyacen a esta realidad destacan el paulatino y creciente cambio de mentalidad por parte de las empresas, que empiezan a apostar por la diversidad y las políticas de inclusión como palanca de competitividad ${ }^{36}$. Todo ello unido a factores como el desarrollo de la tecnología inclusiva o las adaptaciones tecnológicas, posibilita el acceso de las PCD a puestos de trabajo a los que antes no tenían acceso.

Sin embargo, a pesar de los citados avances, la desigualdad de las PCD en disposición de trabajar continúa siendo un caballo de batalla importante. De un lado, los Centros Especiales de Empleo, siguen configurándose como nichos fundamentales para la

\footnotetext{
34 Vid. AluJA Fernández, Rosa Ana., "La transversalidad de los Derechos Humanos en las políticas públicas y su eficacia en períodos de crisis", en VVAA: El derecho internacional de los derechos humanos en períodos de crisis: estudios desde la perspectiva de su aplicabilidad, BONET I PÉREZ, Jaume y SAURA ESTAPÀ, Jaume (Coords.), 2013, p. 31-52.

${ }^{35}$ Vid. "Gestión de las discapacidades en el lugar de trabajo". Repertorio de recomendaciones prácticas de la OIT. Oficina Internacional del Trabajo. Ginebra, 2002. (Disponible en: http://www.ilo.arg/).

${ }^{36}$ Según un informe de ADECCO: VIII Informe de Tecnología y Discapacidad, 2019, p. 7 y ss.
} 
integración laboral de $\mathrm{PCD}^{37}$. Y en cuanto a la contratación ordinaria, los discapacitados todavía se enfrentan a estereotipos instaurados, tales como su bajo rendimiento y poca productividad, absentismo laboral por enfermedad, falta de inclusión en el equipo, incomodidad de los clientes a la hora del trato, o problemas de adaptabilidad con él entorno físico ${ }^{38}$. El resultado es que solo uno de cada cuatro discapacitados en edad laboral trabaja $(25,9 \%)$, frente al $64,4 \%$ de la población general $^{39}$.

En las MCD, la tasa de empleo es prácticamente la mitad (24,9\%) que en las mujeres sin discapacidad ${ }^{40}$, dato que constituye un indicador del fuerte impacto de la discapacidad en el empleo. De nuevo aquí la condición de ser mujer dificulta el acceso laboral, pues el desempleo es mayor que entre los varones. A todo ello se añade el que, la reserva de plazas que establece la ley como forma de discriminación positiva hacia este colectivo (artículo 42 LGD), se incumple sistemáticamente tanto por las empresas privadas como por la administración pública ${ }^{41}$, siendo simbólico e insatisfactorio el grado de cumplimiento de la cuota de reserva (2\%). Ni siquiera la perspectiva de que la contratación de trabajadores discapacitados supone una ventaja para el negocio por los beneficios económicos y fiscales que conlleva, ha terminado de persuadir a las empresas. De hecho, las bonificaciones en la cuota a la Seguridad Social para favorecer la incorporación al mercado laboral de los trabajadores con discapacidad mediante un contrato de trabajo estable ${ }^{42}$, constituyen un incentivo a las empresas que resultó eficaz en su momento. Sin embargo, también pone de manifiesto que, en ausencia de dichos incentivos, la probabilidad que tienen las PCD

\footnotetext{
${ }^{37}$ Moratalla Santamaría, Pablo, "Centros Especiales de Empleo", CIRIEC - España., Revista jurídica de economía social y cooperativa, $\mathrm{n}^{\circ}$ 29, 2016, p. 235-274.

${ }^{38}$ Sobre la necesidad de erradicar las percepciones negativas del trabajo desarrollado por discapacitados, vid. SCUDIERI, Laura, GUAGLIANONE, Luciana, Escudero, Ricardo, y CRESPo PURAS, Carmen, Inclusión sociolaboral..., op. cit., p. 59 y 60.

39 "Informe Olivenza 2019 sobre la situación general de la discapacidad en España”, p. 321.

${ }^{40}$ Informe "Mujer con discapacidad...", op. cit., p. 26.

${ }^{41}$ FERNÁNDEZ ORRICO, Francisco Javier, "Cuotas de reserva y ajustes razonables para trabajadores con discapacidad en el ámbito laboral ordinario", Revista Española de Derecho del Trabajo, n 195, 2017 parte Estudios, Editorial Aranzadi, S.A.U., Cizur Menor, 2017, p. 16.

${ }^{42}$ Bonificaciones en la cuota de la Seguridad Social que van desde los 3.500 Euros y pueden ascender hasta los más de 6.000 dependiendo del grado de discapacidad, sexo y edad del trabajador además del tipo de contrato y jomada laboral. En buena lógica, los contratos temporales recibirán una bonificación inferior al contrato indefinido. La regulación de las reducciones y bonificaciones de cuotas a la Seguridad Social para las personas con discapacidad se regulan fundamentalmente, en el caso de los trabajadores por cuenta ajena, en el Real Decreto Legislativo 1/2013, de 29 de noviembre, Ley 43/2006, de 29 de diciembre y Ley 45/2002, de 12 de diciembre. Vid. SEPE: Guía de Bonificaciones y Reducciones a la Contratación Laboral, abril 2019, p. 4 y 5

(Disponible en: file:///C :/Users/Usuario/AppData/Loca]/Teiiip/BR_SS_GUlA_GENERAL_2020,pdf).
} 
de acceder al mercado laboral mediante un contrato indefinido es muy escaso o nulo. Asimismo, se demuestra que este incentivo a la contratación de discapacitados suele beneficiar sobre todo al colectivo masculino. En concreto, según el $\mathrm{INE}^{43}$, de los trabajadores discapacitados que tienen bonificaciones/reducciones en las cotizaciones para el año 2019, 30,9\% son hombres frente al 21, 4\% de mujeres.

En síntesis, necesitamos cambiar el discurso aprehendido y estereotipado respecto a la contratación de PCD, por cuanto que limita el talento a un perfil determinado ${ }^{44}$. La contratación de discapacitados, refuerza la política de diversidad de las empresas, dando como resultado una cultura corporativa abierta, sin prejuicios, en sintonía con la sociedad y, por tanto, más competitiva, mejora del clima laboral, y refuerza la imagen y reconocimiento social de una empresa, convirtiéndola en un modelo a seguir para otras. A esta conclusión llegan, precisamente, la Fundación ONCE y Reputation Institute, en su reciente estudio "El impacto de la inclusión laboral y social de las personas con discapacidad en la reputación empresarial" 45 . Uno de los principales objetivos ha sido demostrar empíricamente lo que ya se intuía y es que, las empresas que son percibidas con un nivel alto en sus políticas de inclusión laboral y social de las PCD, ven beneficiada su reputación y el apoyo que reciben, lo que implica un impacto positivo en su cuenta de resultados.

- Clara segregación horizontal y vertical en el empleo. Hay que terminar con las dificultades de las MCD a la hora de acceder a determinadas profesiones y dificultades para poder desarrollarse profesionalmente. En términos absolutos, la ocupación mayoritaria para las MCD es la de trabajadoras de los servicios de restauración, personales, protección y vendedoras, que emplea 2.470 .400 mujeres ${ }^{46}$. Y hay que destacar la proporción de mujeres en algunas de las ocupaciones, por ejemplo, las empleadas contables, administrativas y otras empleadas de oficina suponen un $66 \%$, y las que ocupan puestos en ocupaciones elementales, es decir, trabajadoras no cualificadas, suponen casi un $60 \%$. Con respecto a las ocupaciones donde las mujeres no tienen mucha o casi ninguna representación son las siguientes: trabajadoras cualificadas en el sector agrícola, ganadero, forestal y pesquero $(18,91 \%)$, artesanas y trabajadoras cualificadas de las industrias manufactureras y la

\footnotetext{
${ }^{43}$ INE: Empleo de las Personas con Discapacidad (EPD)-Año 2019, p. 7 y 8.

44 GIL GARCÉS, Esteban, "Discapacidad, empleo y nuevas tecnologías”, Revista de Trabajo y Seguridad Social, CEF, no 204, 2000, p. 113.

45 (https://www.fecetc.org/wp-content/uploads/2019/09/190927-informe_inclusion_y_reputacion_Bequal. pdf). Vid. p. 20 y ss.

46 Observatorio de las Ocupaciones 2019. Informe del Mercado de Trabajo de las Personas con Discapacidad Estatal, Servicio Público de Empleo Estatal (SEPE), p. 36 y ss.
} 
construcción $(7,69 \%)$, operadoras de instalaciones y maquinaria y montadoras $(12,69 \%)$, y, por último, las empleadas en ocupaciones militares $(8,88 \%)$.

Estamos ante el llamado "techo de cristal", metáfora creada para referirse a la existencia de barreras invisibles que encuentran las mujeres a la hora de abrirse paso en su carrera profesional e ir progresando hacia puestos de mayor responsabilidad ${ }^{47}$. A esto añadimos otra barrera como la falta de visibilidad femenina, ya que provoca muchos prejuicios sobre las capacidades de las mujeres para acceder a esos puestos de responsabilidad o recibir galardones por su trabajo. Por otro lado, la infravaloración tradicional del trabajo de las mujeres hace que éstas necesiten de más esfuerzo para estar igual de legitimadas, llegando a estar en muchas ocasiones sobrecualificadas para los puestos que desempeñan. Como se ha expresado ${ }^{48}$, se aprecia que las MCD se encuentran concentradas en unas determinadas ocupaciones, lo que pondría de manifiesto la posible existencia de una desigualdad en el mercado de trabajo, con respecto a las mujeres sin discapacidad, que podría derivar en diferencias en los salarios, las condiciones laborales o los ascensos profesionales. Esto significa que las MCD están sobrerrepresentadas o infrarrepresentadas según la ocupación.

- Brecha salarial. Existen diferencias salariales en contra de las PCD, señalando que estas cobran entre un 15 y un $20 \%$ menos en promedio ${ }^{49}$. Los hombres discapacitados cobran un $21,2 \%$ en percepciones integras anuales y un $13,9 \%$ al día a jornada completa. Además, se ha verificado que las mujeres están siendo ocupadas en mayor proporción en aquellas empresas que están obligadas por ley a mantener la cuota de reserva para PCD de 50 o más trabajadores. El salario medio bruto anual de las MCD es de 17.365 euros, frente al de los hombres con discapacidad que es de 20.614,2 euros. La brecha salarial se agrava si se comparan los datos con la remuneración de la población sin discapacidad (25.924,43 euros los hombres y 20.131,41 euros las mujeres $)^{50}$.

Existe una clara necesidad de que las administraciones impulsen políticas de activación sociolaboral de las MCD que incidan en la formación, como fase previa

\footnotetext{
47 Cordero Martín, Guadalupe y Garrido Reina, Paloma, "Intervenir en el techo de cristal desde prácticas innovadoras", Revista Educativa Hekademos, 18, Año VIII, diciembre 2015, p. 12.

${ }^{48}$ CARRIZOSA PRIETO, Carlos, "La segregación ocupacional de las personas con discapacidad en España", Anales de economía aplicada 2007 / coord. B. Moyano Pesquera, Pedro, Somarriba Arechavala, Noelia; FernáNDEZ ARUfE, Josefa (dir.), y RoJo GARCÍA, José Luis (dir.), vol. 9, 2007, p. 50-68.

${ }^{49}$ CERMI. Manual para la negociación colectiva inclusiva en Materia de discapacidad, ed. CINCA, junio 2013, p. 26.

${ }^{50}$ Cfr. 5 Informe General del Observatorio sobre discapacidad y Mercado de trabajo en España, p. 62.
} 
para alcanzar la plena participación en el empleo. Estas políticas deben ir dirigidas prioritariamente a aquellas MCD que se enfrentan a más obstáculos a la hora de encontrar trabajo, especialmente las mujeres con discapacidad intelectual o del desarrollo, así como las mujeres del entorno rural y con pluridiscapacidades, articulándose los apoyos en el empleo que, en cada caso, sean precisos.

- Serias dificultades para obtener estudios profesionales competitivos. El nivel educativo es un elemento fundamental en la incorporación al mercado laboral y emerge como variable claramente vinculada a la actividad laboral; así, a mayor nivel de estudios, mayor tasa de actividad ${ }^{51}$. En España, ha aumentado sensiblemente el porcentaje de jóvenes con estudios universitarios y nuestro país se encuentra entre los países europeos que presentan un mayor porcentaje de jóvenes con estudios superiores $(42,3 \%)^{52}$, en línea con el objetivo establecido por la Estrategia Europea $2020^{53}$. Asimismo, el porcentaje de mujeres sin discapacidad que han obtenido un nivel formativo superior es del 48,6\%, mientras que esta misma tasa para las MCD es de un $34,2 \%$.

También la población sin discapacidad que está empleada, en general, tiene una mayor formación, siendo más alta la proporción de mujeres con estudios universitarios (47,8\% en 2015) que de hombres (37,7\%). Las MCD que trabajan están más formadas que los varones. Del colectivo de interés con estudios universitarios, el 55,5\% son mujeres, mientras que del grupo que no tiene formación, no alcanza el $30 \%{ }^{54}$. Este resultado es importante, puesto que muestra cómo la participación de las mujeres en el mercado laboral viene precedida de una mayor formación, y se traduce en que, las personas que poseen estudios universitarios, tienen una probabilidad de acceder a un contrato indefinido de 11,6 puntos porcentuales mayor que las que carecen de esta formación y, además, la probabilidad de pasar a un contrato indefinido, habiendo estado sin empleo durante los dos años anteriores, es 6 puntos porcentuales superior que la de un trabajador sin formación.

Con todo, es generalizada tanto en mujeres como hombres con discapacidad, su formación media-baja. De hecho, a lo largo de su vida profesional, el $80 \%$ de los trabajos que desempeñan las PCD son de cualificación baja o media en consonancia con su nivel de estudios. La Encuesta del INE sobre "Inserción Laboral de Titulados Universitarios 2019", pone de relieve la muy escasa presencia de estudiantes con discapacidad dentro del alumnado de este nivel educativo; de hecho, los graduados

\footnotetext{
515 Informe General del Observatorio sobre discapacidad y Mercado de trabajo en España, p. 22.

${ }^{52}$ Consejo Económico y Social (CES). Informe 2015. Competencias Profesionales y Empleabilidad.

${ }^{53}$ EUROPE 2020 TARGETS.

${ }^{54}$ Cfr. Informe sobre "Integración en el mercado laboral...”, op. cit., p. 15.
} 
universitarios con discapacidad del curso 2013-2014 presentaban a finales del año 2019 una tasa de actividad del 83,1\%, 10 puntos menos que los graduados universitarios sin discapacidad. La tasa de empleo era del 75,4\% (10 puntos menos que los graduados universitarios sin discapacidad) y la tasa de paro, cinco años después de titularse, era del 9.2\% (un punto más que los graduados universitarios sin discapacidad). Se confirma pues que, todas aquellas políticas dirigidas a fomentar la enseñanza universitaria entre las PCD, tendrán un efecto positivo sobre su incorporación al mercado laboral mediante contratos de trabajo estables. En la sociedad del conocimiento la exclusión está ligada cada vez más a los niveles educativos y no hay duda de que, la formación universitaria, es la mejor garantía de acceso a empleos cualificados y de calidad para las PCD, así como que éste tiene que ser un objetivo para todas ellas. Lamentablemente, todavía son pocos los discapacitados que poseen estudios universitarios, entre un 6 y un $8 \%$, es decir, poco más de 20.000 universitarios con discapacidad. Lo que significa apenas el 1,3\% del total. Desde esta perspectiva, entendemos que es absolutamente preciso revisar los itinerarios y las barreras que existen en las etapas educativas anteriores para favorecer la inclusión de las PCD.

- Temporalidad y trabajo a tiempo parcial. Como ponen de manifiesto los análisis existentes, una misma persona es contratada en el año una media de 2,16 veces, lo que evidencia la temporalidad de la contratación ${ }^{55}$. Tan solo el $9 \%$ de los contratos dirigidos al colectivo con discapacidad tienen carácter indefinido, mientras que la contratación temporal es de un 90,3\% evidenciando de nuevo la precariedad del mercado de trabajo ${ }^{56}$. Atendiendo al tipo de contrato, la precariedad se hace manifiesta con más fuerza. El 37,2\% de los contratos realizados al colectivo se agrupan bajo la categoría de "eventuales, por circunstancias de la producción" y otro $32,2 \%$ corresponde a "obra o servicio". La relación entre discapacidad y trabajo a tiempo parcial se menciona en la mayoría de los estudios sobre la participación laboral de este colectivo.

En un marco en el que las MCD representan el 38,6\% de los contratos realizados, son además ellas las que tienen una mayor posibilidad de permanecer en trabajos a tiempo parcial que los hombres con discapacidad ${ }^{57}$. Es más, puede decirse que, las MCD, siguen siendo las destinatarias de la jornada parcial (25,5\% frente al 10,7\% de

\footnotetext{
55 Informe Olivenza 2019 sobre la situación general de la discapacidad en España, p. 332.

${ }^{56}$ Ibídem, p., 39.

57 PAGÁn RodrígueZ, Ricardo, "Transtions to part-time woric at olderages: The case of people with disabilities in Europe", Disability\&Society, 27 (1), 2012, p. 95-115.
} 
los hombres) ${ }^{58}$, aspecto éste que reafirma su situación de mayor fragilidad estructural, en tanto que la retribución salarial y la posibilidad de promoción profesional asociadas a esta tipología de jornada son menores que las vinculadas a la contratación a tiempo completo ${ }^{59}$. Hay que tener en cuenta, que, en estos sectores, buena parte de la plantilla tiene ocupaciones elementales con bajos salarios. La reducción de la jornada supone que los ingresos percibidos no aseguran la posibilidad de una vida independiente ${ }^{60}$.

- Entornos de trabajo inseguros. Fuera de los Centros Especiales de Empleo, garantizar entornos de trabajo seguros es una circunstancia que no facilita la contratación de PCD, porque genera una conciencia en la empresa de incremento de gastos $^{61}$. Tengamos en cuenta que, a medida que avanza la sociedad del riesgo también lo hace el antagonismo entre los afectados por el riesgo y los que se benefician de ellos ${ }^{62}$. Lo que no varía, es el principio rector de la prevención consistente en adaptar el puesto de trabajo al trabajador y no a la inversa ${ }^{63}$.

Normalmente, las necesidades de los trabajadores con discapacidad deben tenerse en cuenta en la fase de diseño y planificación de la actividad empresarial, siendo aplicable a todas las discapacidades, incluidas las de movilidad, aprendizaje, visuales o auditivas. Cuando no es así, la contratación de discapacitados exige, en la mayor parte de los casos, una inversión económica adicional para adaptar su puesto de trabajo que no todas las empresas están dispuestas a hacer. A ello tampoco ayuda la falta de concreción legislativa y los difusos límites dentro de los que se mueve esta obligación empresarial impregnada de subjetividad.

Con relación a las MCD garantizar entornos de trabajo seguros supone, de manera añadida, proporcionarle un entorno laboral libre de una discriminación, violencia y

\footnotetext{
${ }^{58}$ Cfr. 5 Informe General del Observatorio sobre discapacidad y Mercado de trabajo en España, p. 54.

${ }^{59}$ Mercado García, Esther, Aizpurúa GonZÁlez, Eva y García Vicente, Luis Mariano, “Avanzando hacia la igualdad de oportunidades...”, op. cit., p. 99.

${ }^{60}$ SCUDieri, Laura, GuAglianONE, Luciana, Escudero, Ricardo, y CRESPO PURAS, Carmen, "Inclusión socio-laboral...", op. cit., p. 64 y 65.

${ }^{61}$ Cfr. Moratalla Santamaría, Pablo, "Centros Especiales de Empleo", CIRIEC - España. Revista jurídica de economía social y cooperativa, $\mathrm{n}^{\circ} 29,2016$, p. 235-274.

62 BECK, Ulrich, "Risk Society", SAGE publications, London, 1942, p. 46.

${ }^{63} \mathrm{Tal}$ y como disponen los artículos 4.2.d) del Estatuto de los Trabajadores, 15.d) de la Ley de Prevención de Riesgos Laborales y 40.2 de la LGD. Cfr. sobre la cuestión, Rivas VALLeJo, Pilar, "Derechos fundamentales y prevención de riesgos laborales a la luz de la Ley General de los derechos de las personas con discapacidad". VVAA: Los derechos fundamentales inespecificos en la relación laboral y en materia de protección social, XXIV Congreso Nacional de Derecho del Trabajo y de la Seguridad Social, Pamplona, mayo de 2014 / Asociación Española de Derecho del Trabajo y de la Seguridad Social, p. 2.
} 
acoso, la mayor parte de las veces, invisible ${ }^{64}$. Para ello, una medida importante sería la formación exhaustiva de los trabajadores en materia de igualdad, no discriminación y acoso que tenga en cuenta la necesidad de que las organizaciones acepten la diversidad en todas sus políticas y prácticas. Sus destinatarios principales deberían ser los superiores jerárquicos, los responsables y profesionales de la seguridad y salud, los representantes de los trabajadores y cualquier persona que participe en la evaluación de riesgos y en los comités de seguridad de la empresa.

- Desarrollo de actividades elementales, no monetizadas y economía sumergida. En términos absolutos, la actividad económica donde se contrata a más PCD corresponde al sector servicios que aglutina el $82,7 \%$ de las personas con discapacidad ocupadas, lo que evidencia claramente la terciarización de nuestra economía. Las ocupaciones donde se registran mayores volúmenes de contratos a PCD son: limpieza (43.220), peones de las industrias manufactureras (28.505), conserjes de edificios (7.828) y empleados de ventas de apuestas (5.866). En general, nos encontramos con ocupaciones de baja cualificación centradas en ocupaciones elementales. Derivadamente, esta situación de paupérrima retribución e infracotización, aboca a las MCD a carecer de pensión contributiva y hacer un mayor uso de las no contributivas ${ }^{65} \mathrm{y}$, asimismo, limita o excluye las posibilidades de crear planes de pensiones complementarios o acudir a otros sistemas de previsión social ${ }^{66}$, pese a las condiciones especiales y ventajas adicionales que se otorga a los discapacitados en este ámbito.

Es evidente que, si no se emprenden medidas correctoras y preventivas enérgicas, la situación conduce a incrementar todavía más el porcentaje de discapacitados que vive de la economía sumergida (actividades de prosumo), empleo no declarado, y situaciones de explotación laboral. Con este objetivo, es preciso dar visibilidad y contabilizar todas las contribuciones no monetizadas que las MCD realizan en el ámbito de la reproducción de la vida y que son esenciales para que el sistema económico, tal cual está concebido en la actualidad, siga funcionando. La riqueza de un país no solamente se produce en el "mercado", sino que también existen otras esferas de generación de servicios tradicionalmente ignoradas cuya responsabilidad

\footnotetext{
${ }^{64}$ INIESTA MARTíneZ, Almudena y MUÑoz SÁNCHEZ, Práxedes, "Invisibilidad de la violencia de género en mujeres con diversidad funcional", International Journal of Developmental and Educational Psychology. Revista de Psicología, vol. 4, n 1, 2017, p. 195-202.

${ }^{65}$ GIMÉNEZ LÓPEZ, Dulce y RAMOs LORENTE, María del Mar, "La discriminación de las mujeres discapacitadas en España”, Revista del Ministerio de Trabajo e Inmigración, nº 45, 2003 (Ejemplar dedicado a: Asuntos sociales), p. 61-76.

66 Malo Ocaña, Miguel Ángel, CUeto Iglesias, Begoña, y RodríGuEZ Álvarez, Vanesa, "Compatibilizando pensiones por discapacidad y empleo en España", Papeles de economía española, $\mathrm{n}^{\circ}$ 161,2019 , p. 55-70.
} 
sigue recayendo en las mujeres ${ }^{67}$. En este contexto, como se verá a continuación, fomentar el autoempleo de los discapacitados debe ser otra medida prioritaria por parte de las políticas públicas, de modo que las PCD y, particularmente, las MCD puedan desarrollar sus propios negocios.

- Débil fomento institucional del emprendimiento de los discapacitados. Normativamente, el fomento del emprendimiento también ha alcanzado a las PCD. Ello, a través de incentivos fiscales y de Seguridad Social a quienes se establezcan como trabajadores por cuenta propia, a tenor de la Ley 11/2013, de 26 de julio, de medidas de apoyo al emprendedor y de estímulo del crecimiento y de la creación de empleo y la Ley 14/2013, de 27 de septiembre, de apoyo a los emprendedores y su internacionalización. Por tanto, cierto es que se vienen arbitrando medidas de apoyo para incentivar al emprendedor discapacitado que se establezca como autónomo ${ }^{68}$. En concreto, el artículo 32 LETA, en redacción aportada por el artículo 4 de la Ley 6/2017, de 24 de octubre y apdo. 4, D.F. 3 del Real Decreto-ley 28/2018, de 28 de diciembre, para la revalorización de las pensiones públicas y otras medidas urgentes en materia social, laboral y de empleo, regula las reducciones y bonificaciones de cuotas a la Seguridad Social para las PCD que se establezcan como trabajadores por cuenta propia.

También se han establecido, desde 2019, beneficios en la cotización a la Seguridad Social para las MCD, inicial o sobrevenida, víctimas de violencia de género y víctimas del terrorismo que se establezcan como trabajadores por cuenta propia. Y una de las novedades 2020 de la Seguridad Social, ha sido la actualización de las ayudas de las Mutuas, mediante complementos para ayudar a los autónomos que sufren alguna discapacidad, tras haber sufrido un accidente laboral o enfermedad profesional. Sin embargo, conviene no llevarse a engaños, pues la realidad arroja unos resultados lamentables en este ámbito. El volumen de PCD en alta en el Régimen Especial de Autónomos para 2017, apenas representa el 1,43\% sobre el total de afiliados (el 0,66 \% sobre el total de autónomos), frente al el 16,29\% en los autónomos sin discapacidades ${ }^{69}$. Además, se trata de un corpúsculo generado en gran medida por la reincorporación al mercado laboral de personas con discapacidades sobrevenidas, en el marco de una compleja casuística de incapacidades permanentes.

\footnotetext{
${ }^{67}$ NIETO RoJAs, Patricia, "Políticas de protección a los menores con discapacidad, dependientes o enfermos crónicos. En especial, su recepción por la Seguridad Social y el Sistema para la Autonomía y Atención a la Dependencia", Revista Española de Derecho del Trabajo, n 217, 2019 parte Estudios, Editorial Aranzadi, S.A.U., 2019, p. 162.

69 Observatorio de las Ocupaciones 2019. Informe del Mercado de Trabajo de las Personas con Discapacidad Estatal (datos 2018), p. 25 y ss.
} 
Se necesita pues, fomentar el espíritu emprendedor, específicamente, digital, a través de medidas en educación, innovación y políticas fiscales específicas que estimulen la actividad $^{70}$. Desde este último plano, convendría además asignar recursos suficientes a los servicios existentes de financiación pública, y adoptar las medidas oportunas para eliminar los obstáculos de acceso a la microfinanciación.

- Un entorno familiar que suele actuar como factor impeditivo de acceso al empleo o mantenimiento del puesto de trabajo. Como sujeto activo de empleo, curiosamente, una de las dificultades principales para que la MCD acceda al mercado de trabajo laboral procede, fundamentalmente, de la sobreprotección de su entorno familiar ${ }^{71}$, y la creencia de que la incapacidad le va a impedir poder desarrollar una vida laboral plena. El miedo del propio entorno familiar de la discapacitada a que no se adapte es el que, en muchas ocasiones, obstaculiza esa integración laboral ${ }^{72}$.

Como receptores de cuidado, la situación del discapacitado provoca en ocasiones un efecto colateral determinante en el entorno laboral de sus familiares, que muchas veces culmina con la pérdida del empleo de éstos ${ }^{73}$, especialmente si son mujeres. De hecho, buena parte de la inactividad femenina obedece a la asunción de responsabilidades familiares; correlación que se incrementa en el caso de los menores con discapacidad, dependientes o con una enfermedad crónica ${ }^{74}$. Hay que lograr la conciliación laboral efectiva de las familias que tienen personas con discapacidad, mediante apoyos institucionales para que el familiar-cuidador (normalmente mujer) pueda mantenerse en el mercado de trabajo.

El mismo problema se observa cuando es la MCD la proveedora de esos cuidados. Para describir un mapa completo de la realidad actual, es necesario hacer un apunte a la actual situación de pandemia dada su negativa incidencia en múltiples ámbitos del mundo de la discapacidad. Concretamente, la COVID-19 ha provocado la pérdida de la autonomía del discapacitado por una mayor dependencia de terceras personas y de necesidades de apoyo no cubiertas o por el contrario, por tener mayores responsabilidades familiares de cuidado de mayores o menores; como se pone de

\footnotetext{
${ }^{70}$ CEOE. "Plan Digital 2020...”, op. cit., p. 6.

${ }^{71}$ Matriz cultural de la sobreprotección que se constituye en respuesta a las condiciones sociales que, históricamente, han constituido él ambiente en que las familias y las personas que presentan discapacidad han debido desenvolverse, como pone de manifiesto AVARIA SAAVEDRA, Andrea, "Discapacidad: Exclusión/ Inclusión”, Revista de la Maestría de Antropología y Desarrollo, n 5, 2001, p. 10 y 11. (Disponible en http:/www. rehue. csocáales.uchile. el).

72 Mercado García, Esther, AizPurúa GonzÁlez, Eva y García Vicente, Luis Mariano, “Avanzando hacia la igualdad de oportunidades...”, op. cit., p. 99.

${ }^{73}$ Fundación Adecco; Previsora Bilbaíno Seguros, Informe Discapacidad y Familia, 2018, p. 4.

${ }^{74}$ Nieto Rojas, Patricia, "Políticas de protección a los menores con discapacidad...”, op. cit., p. 164.
} 
manifiesto en un informe reciente ${ }^{75}$, un $31 \%$ de las mujeres entrevistadas consideran que su responsabilidad en relación a los cuidados aumentó bastante o mucho con la pandemia. A la luz del escenario descrito, es clara la necesidad de impulsar políticas de promoción de la autonomía personal y de atención a las personas en situación de dependencia que, en el marco de una política de cuidados (concebida desde un enfoque de derechos humanos), tenga en consideración la realidad de las MCD, no solamente como receptoras de cuidado, sino también como proveedoras del mismo, circunstancia que suele ignorarse de manera sistemática.

Potenciar estas políticas ha de ser un asunto de Estado, en un contexto en el que muchas trabajadoras se ven abocadas al abandono total o parcial de su carrera, debido a unas responsabilidades familiares que no pueden compatibilizar con su desempeño profesional. La Administración Pública debe proporcionar un marco legal que, acompañado del compromiso de las empresas, permita que dicha conciliación sea real y efectiva. Con este objetivo, convendría introducir la discapacidad como supuesto del artículo 34.8 ET (adaptaciones de la duración y distribución de la jornada de trabajo, en la ordenación del tiempo de trabajo y en la forma de prestación), dado que no lo contempla como excepción y, en esa medida, las necesidades adicionales de las familias que tienen PCD no quedan cubiertas. Se propone promover un marco legal que amplíe esta normativa, garantizando fórmulas como la utilización de la jomada continua, el horario flexible u otros modos de organización del tiempo de trabajo y descansos que faciliten la compatibilidad de la conciliación de la vida personal y profesional de las PCD o de los trabajadores que conviven con ellas.

Dado que la experiencia nos indica que, cerrar con éxito reformas que modifiquen la norma y la reorienten hacia una mejor atención a algunos subcolectivos, no es fácil, complementariamente, sería muy efectivo utilizar también políticas de la Administración Pública ajenas al Derecho del Trabajo, como puede ser una incisiva política de intervención familiar o educativa, por mencionar dos ámbitos que pueden repercutir positivamente en un aumento de la tasa de empleo y de actividad de las $\mathrm{MCD}^{76}$.

\footnotetext{
${ }^{75}$ Vid.: Informe de detección de necesidades de las mujeres con discapacidad. Impacto de la COVID-19, elaborado por la Confederación Española de Personas con Discapacidad Física y Orgánica (COCEMFE), 2020.

${ }^{76}$ Scudieri, Laura, Guaglianone, Luciana, Escudero, Ricardo, y Crespo PURAs, Carmen, Inclusión socio-laboral de las mujeres..., op. cit., p. 60.
} 
- Desempleo, pobreza y exclusión social. Las tasas de pobreza y exclusión entre las PCD son manifiestamente mayores que las del resto de la población ${ }^{77}$. Si ya antes de la crisis, el 28,7\% de las personas con discapacidad en la UE se encontraba en situación de riesgo de padecer pobreza, y tan solo el 50,8\% tenía un empleo, la pandemia por COVID ha terminado de agravar la situación. De hecho, 1.208.900 PCD en edad activa, se encuentran fuera del mercado laboral. Además, los contratos a PCD han caído un 22,8 por ciento entre febrero y marzo, pasando de los 9.082 a los 7.397 y han dejado en el primer trimestre del año la cifra más baja de contratación desde 2016, con 25.811 contratos, que suponen un 7,7 \% menos que el mismo periodo de 2019.

En el caso de las MCD, el 6,5\% se encuentra en situación de pobreza severa y un $17,3 \%$ en situación de pobreza moderada ${ }^{78}$. El riesgo de pobreza afecta al 30,4\% de las MCD, 6 puntos más que la población sin discapacidad ${ }^{79}$. Ello sin contar con que muchas PCD que trabajan (como se ha visto, especialmente mujeres), tienen contratos tan precarios y salarios tan bajos, que gozan de escasa o nula garantía de protección a la luz del cierre de las empresas ${ }^{80}$. Para paliar esta situación y hacer frente a la reconstrucción tras la pandemia del coronavirus, el CERMI y el EDF piden destinar recursos suficientes de la UE para los grupos sociales en riesgo de exclusión, incluidas las PCD.

Asimismo, la tasa de paro de las MCD es de 25,0\%, 10 puntos superior a la de la población sin discapacidad ${ }^{81}$, habiendo, entre los parados de larga duración, una mayor presencia femenina.

Existe pues una elevada incidencia del desempleo, el trabajo informal y la precariedad laboral en personas con baja formación y en grupos de población con mayor riesgo de exclusión (inmigrantes, población gitana, personas con discapacidad y personas trabajadoras mayores), con especial incidencia en las mujeres, así como un elevado porcentaje de personas en riesgo de pobreza y exclusión social, en general, y, especialmente, la infantil y juvenil. A mayor abundamiento, las PCD tienen más dificultades para superar todas las crisis, viéndose especialmente abocadas a la precariedad de la economía sumergida o al paro de larga duración.

\footnotetext{
${ }^{77}$ CERMI, Derechos humanos y discapacidad Informe España, 2019, p. 388.

78 “Informe Olivenza 2019 sobre la situación general de la discapacidad en España”, p. 305 y ss.

${ }^{79}$ Cfr. $9^{\circ}$ Informe AROPE 2019, p. 16.

${ }^{80}$ RodríGuez Álvarez, Vanessa y Cueto IGLesias, Begoña, “El trabajo de las personas...”, op. cit., p. 6.

${ }^{81}$ INE, 2018.
} 


\section{La mujer discapacitada frente al nuevo desafío de un mercado de trabajo digitalizado}

Los avances tecnológicos tienen una muy estrecha relación con la inclusión de las PCD y se han convertido en aliados imprescindibles al mejorar, en términos generales, su calidad de vida ${ }^{82}$. Sin embargo, la hoja de ruta actual va dirigida a fijar la mirada más allá del hogar de las PCD para reconfigurar su participación en el mundo del trabajo. Discapacidad y revolución digital son dos variables, pues, destinadas a entenderse como reto en un futuro próximo. En concreto, las nuevas tecnologías de la información y la comunicación (NNTT) son una formidable herramienta para mejorar la integración laboral y un auténtico proyector del talento y capacidades de estos empleados. Pero también pueden convertirse en una nueva e insalvable barrera para muchas PCD si no se trazan las adecuadas políticas públicas; no olvidemos la polarización del mercado laboral que provoca la digitalización, creando, por un lado, empleos de alta formación y altos salarios y, devaluando, por otro, gran parte del trabajo no especializado ${ }^{83}$.

Para las MCD el problema se ve agravado dado que, el género, es uno de los condicionantes fundamentales que inciden en esa brecha, configurando un análisis específico común a todas las sociedades ${ }^{84}$. La brecha digital de género las enfrenta a un verdadero peligro de quedar excluidas de estos avances, como puso de relieve el Foro Europeo de Discapacidad (en adelante, FED) en su "Manifiesto sobre la Sociedad de la Información y la Discapacidad" $"$, de modo que, en la actualidad, las MCD no tienen garantía de que la Sociedad de la Información vaya a mantener la promesa de convertirse en una sociedad totalmente accesible para todos. La competencia por el talento digital será creciente, y más aún en un contexto en el que el mercado laboral está cambiando y cambiará más radicalmente a medida que se vayan implantando nuevas tecnologías. Surge la certeza de una obsolescencia programada que sitúa a los trabajadores frente a una frontera inexpugnable solo capaz de ser derribada por la formación continua, permanente e infinita ${ }^{86}$. En este contexto, no se puede seguir formando para un mundo que ya no existe ${ }^{87}$.

\footnotetext{
${ }^{82}$ Como pone de relieve la Encuesta de la Fundación Adecco y Keysight Technologies Spain, (Disponible en: https://fimdacioiradecco.org/informe-tecnologia-y-discapacidad/).

${ }^{83}$ Cfr. último e interesantísimo informe de MIT Work of the Future (fall 2019 report).

${ }^{84}$ CARIACEDO PÉREZ, Lola, "Mujeres Jóvenes y nuevas tecnologías...”, op. cit., p. 166 y 167.

${ }^{85}$ Foro Europeo de Discapacidad; Manifiesto Europeo, ante la Sociedad de la Información y las Personas con Discapacidad, p. 10 y 15. (DOC EDF 99/3).

${ }^{86}$ CARRIZOSA PRIETO, Esther, "Lifelong learning e industria 4.0. Elementos y requisitos para optimizar el aprendizaje en red", Revista Internacional y Comparada de Relaciones Laborales y Derecho, $\mathrm{n}^{\mathrm{0}}$ 1, vol. 6 , 2018, p. 42 y ss.

${ }^{87}$ Por cada seis empresas españolas que requieren los servicios de un profesional TIC, solo hay un perfil capacitado y formado para asumir este trabajo. Son datos extraídos del estudio "Empleabilidad y talento
} 
Asimismo, la actual situación de pandemia ha incrementado un balance negativo al respecto, como ponen de manifiesto los datos. Según el informe del $\mathrm{COCEMFE}^{88}$, más del $38 \%$ de las MCD participantes en su encuesta considera que la brecha digital ha empeorado en su situación actual bastante o mucho, y que la interrupción en la atención presencial de los servicios públicos, ha dificultado el acceso a recursos y apoyos necesarios para minimizar el impacto negativo de la crisis sanitaria de la COVID-19. Son tiempos de oportunidad, pero también de temor. Se trata del miedo natural a que todas estas tendencias de cambio, coyunturales o definitivas, generen y aumenten todavía más la inseguridad económica y la desigualdad existente en un ámbito tan central de la vida como el empleo. No podemos olvidarnos del desarrollo acelerado de la inteligencia artificial, los algoritmos y el impacto que la robotización y los procesos de automatización están teniendo en el empleo, la destrucción de puestos de trabajo y el descenso de las cotizaciones. Para contribuir a la creación de un nuevo marco de referencia en este ámbito, contamos con la ventaja de que, el proceso de cambio, todavía se encuentra a una escala reducida, con lo cual, es el momento idóneo para abordar y gestionar los posibles impactos que pueda tener sobre el trabajo ${ }^{89}$.

Es fundamental, para empezar, fomentar un ecosistema nacional para el desarrollo y el reconocimiento del talento habilitador de la transformación digital en España con el fin de promover, educar y formar en las nuevas competencias digitales que demandan las organizaciones del sector TIC y otros sectores que están en el proceso de digitalización ${ }^{90}$. Y es preciso identificar todos los posibles riesgos de exclusión digital y actuar tanto con medios públicos como privados, para evitar cualquier brecha y favorecer la inclusión digital de las $\mathrm{PCD}^{91}$, especialmente, sabiendo que existe y persiste una generalizada infrarrepresentación de las mujeres en sector TIC y también entre las profesiones con especialización en dichas tecnologías ${ }^{92}$. Si queremos evitar que el trabajo de las PCD y, de la MCD, en particular, quede abocado a servicios manuales de baja cualificación, la formación y el reciclaje deberán ser obligados y orientarse hacia la empleabilidad, pues,

digital 2019”, elaborado por la Fundación VASS y la Universidad Autónoma de Madrid (UAM), que ponen en evidencia el gran déficit de talento digital que sufre nuestro país.

${ }^{88}$ Vid.: Informe de detección de necesidades de las mujeres con discapacidad..., op. cit.

${ }^{89}$ Cfr. informe: El mercado laboral digital a debate. Plataformas, Trabajadores, Derechos y WorkerTech, Fundación Cotec, 2019, p. 56.

${ }^{90}$ Cfr. Manifiesto por el liderazgo de la transformación digital de la economía española mediante el desarrollo del talento, elaborado por Ametic, CCOO y UGT, 2017, p. 4.

${ }^{91}$ Vid. TORRES GONZÁLEZ, Arancha, "Inclusión Digital, un plan de acción para combatir el analfabetismo y la exclusión digital", Capital humano: revista para la integración y desarrollo de los recursos humanos, $\mathrm{n}^{\mathrm{o}} 348,2019$, p. 15.

92 MARTínez-Cantos, José Luis y CASTAÑo Collado, Cecilia, "La brecha digital de género y la escasez de mujeres en las profesiones TIC", Panorama Social, n 25, 2017, p. 53. 
si el avance del mercado es rápido, tanto más deberá serlo la adaptación como clave de oportunidad.

En el "Plan Digital 2020" de la $\mathrm{CEOE}^{93}$, uno de los capítulos más importantes es el dedicado a eliminar todo tipo de brechas digitales provocadas por motivos diversos, incluida la discapacidad. Este Plan, que pretende influir tanto en las asociaciones empresariales que abarca la organización, como en el Gobierno, partidos, asociaciones, instituciones y sindicatos, puede ser un ejemplo a seguir. Pero además, como medidas complementarias a las políticas públicas que gestionen en este ámbito, quizá no estaría de más, de un lado, la creación de un observatorio de brecha digital con participación de todos los sectores implicados, incluidas, especialmente, las asociaciones de personas con diversidad funcional, que elabore los indicadores de referencia para la medición de los diferentes tipos de brecha y proponga los objetivos a lograr anualmente para la eliminación de barreras ${ }^{94}$, y, de otro, diseñar un catálogo de cursos de formación digital para ayudar a colectivos vulnerables.

Por tanto, particularmente determinante será que las MCD no se queden fuera del proceso de transformación digital que afecta al mercado laboral, y superar así, como hemos puesto de manifiesto supra, la segregación horizontal y vertical a las que se ven sometidas. Para ello, es necesario promover políticas que contemplen la utilización activa de las tecnologías de la información de cara a facilitar la inserción laboral de las PCD con carácter general y, en particular, respecto de los colectivos más desfavorecidos que en la actualidad no disfrutan de igualdad de oportunidades en el empleo. Dado que la mayoría de las contrataciones se han realizado en Centros Especiales de Empleo ${ }^{95}$, es vital plantearse la necesidad de aproximar las necesidades de las PCD al ámbito tecnológico y empresarial. Las empresas ordinarias deben poder contar con soluciones accesibles para las PCD, disponiendo de entornos más abiertos y proclives a su incorporación ${ }^{96}$.

\section{Nuevos itinerarios de las políticas públicas para afrontar el problema}

\subsection{El eje de actuación normativa de las politicas públicas en materia de discapacidad}

Aunque es cierto que el colectivo de PCD ha constituido un eje de actuación prioritario en las políticas públicas sociales desarrolladas en los últimos años, y ha experimentado cambios importantes, pasando de políticas tradicionales basadas en transferencias de renta y subsidios, hacia políticas más activas centradas en la integración efectiva en el

\footnotetext{
${ }^{93}$ CEOE. Plan Digital 2020: la digitalización de la sociedad española, 2017, p. 134 y ss.

${ }^{94}$ Ibídem, p. 135.

${ }^{95}$ Cfr. Real Decreto 2273/1985.

${ }^{96}$ Cfr. VIII Informe de Tecnología y Discapacidad, 2019, p. 16 y ss.
} 
mercado laboral y en la sociedad ${ }^{97}$, la integración sociolaboral solo se podrá considerar efectiva para las PCD cuando exista absoluta igualdad en el acceso y condiciones laborales respecto a cualquier otro trabajador sin discapacidad.

Tanto en el derecho internacional como en las legislaciones nacionales, la discriminación positiva es el instrumento clave de una política de reducción de las desigualdades entre los diferentes grupos sociales. Pretende promover una mayor igualdad de hecho o, por lo menos, garantizar a los miembros de los grupos con desventaja una verdadera igualdad de oportunidades. En consecuencia, el principal objetivo de las políticas públicas en esta materia ha sido y es conseguir la plena igualdad de oportunidades, la no discriminación, la accesibilidad universal y el ejercicio real de derechos por parte de las PCD en igualdad de condiciones respecto con el resto de ciudadanos.

A la consecución de estos objetivos responde el desarrollo del Real Decreto Legislativo 1/2013, de 29 de noviembre, por el que se aprueba el Texto Refundido de la Ley General de derechos de las personas con discapacidad y de su inclusión social (en adelante, LGD). El fin de esta norma es armonizar, unificar y actualizar el complejo marco normativo precedente $^{98}$, ya derogado, desde el prisma de los derechos, y conforme a lo previsto en la CIDPCD.

Pues bien, el capítulo VI de la LGD, bajo la rúbrica de "derecho al trabajo", recoge las garantías del mismo, la no discriminación directa e indirecta y la igualdad de trato. Sigue el esquema de la antigua Ley 13/1982 de 7 de abril, de Integración Social de Minusválidos (LISMI) y toma los preceptos sobre la no discriminación y las medidas de acción positiva de la Ley 51/2003, de 2 de diciembre, de igualdad de oportunidades, no discriminación y accesibilidad universal de las personas con discapacidad (LIONDAU). En concreto, la norma distingue diversas vías de participación laboral, de modo directo: el empleo ordinario; los centros especiales de empleo y el empleo autónomo; e, indirectamente, la posibilidad de subvenciones a la contratación y bonificaciones en la cuota de la Seguridad Social. Aunque la intención del legislador ha sido claramente propiciar una compensación

\footnotetext{
${ }^{97}$ Mercado García, Esther, Aizpurúa GonZÁlez, Eva y García Vicente, Luis Mariano, "Avanzando hacia la igualdad de oportunidades en la inclusión socio-laboral de las personas con discapacidad". Cuadernos de Trabajo Social, vol. 26-1, 2013, p. 101. Instituto Nacional de Estadística (INE). Encuesta sobre Discapacidades, Deficiencias y estado de Salud. Avance de resaltados. Datos básicos. Subdirección General de Difusión Estadística e Instituto Nacional de Estadística (INE). Madrid, 2000. (Disponible en web: http://www.ine.es/inebase/cgi/um).

${ }^{98}$ La Ley de integración social de los minusválidos (Ley 13/1982, de 7 de abril); la Ley de Igualdad de oportunidades, no discriminación y accesibilidad universal de las personas con discapacidad (Ley 51/2003, de 2 de diciembre); y la Ley de infracciones y sanciones en materia de igualdad de oportunidades, no discriminación y accesibilidad universal de las personas con discapacidad (Ley 49/2007, de 26 de diciembre).
} 
hacia la brecha productiva que la discapacidad puede suponer como detrimento en el proceso productivo ordinario, el cambio, no ha supuesto, como se razonará, una modificación sustancial de las vías y métodos para la integración laboral de las PCD como medida imprescindible para lograr una vida plena e independiente.

De las dos medidas previstas, la primera, ha intentado superar la asimetría normativa mediante programas de apoyo en el empleo (acompañamiento individualizado para facilitar la adaptación) o el establecimiento de una cuota mínima del $2 \%$ de reserva de puestos de trabajo para PCD, tanto en empresas públicas como privadas (artículo 42 LGD). Ahora bien, su cumplimiento puede estar exento siempre que se justifique debidamente frente a la autoridad laboral y se cumplan una serie de medidas alternativas. Desde el principio de su singladura, ha sido este uno de los aspectos más controvertidos dado que, al flexibilizarla, el propio legislador ha propiciado que las empresas puedan sortear la medida sin problemas, convirtiendo la excepción en regla, alegándose, por sistema, la dificultad de encontrar en número y cualificación suficiente el volumen requerido de trabajadores con discapacidad ${ }^{99}$. Mediante la segunda, se ha previsto la relación laboral de carácter especial de las PCD en los Centros Especiales de Empleo [artículo 2.1.g) ET], al tiempo que ha regulado su creación, la de enclaves laborales (pasarelas para la transición al empleo ordinario) y las compensaciones económicas en atención a las especiales características que concurren y así puedan desarrollar la función social requerida ${ }^{100}$.

Complementariamente a estas medidas, tanto la LGD como la CIDPCD, también trabajan en el desarrollo de los siguientes objetivos:

- La ejecución del Plan de Acción de la Estrategia Española sobre Discapacidad 20142020 en colaboración con las Comunidades Autónomas, con el tejido asociativo de la discapacidad y con el resto de ministerios. Este nuevo plan se distribuye en dos fases diferenciadas. La primera fase ocupa los años 2014 a 2016 y la segunda el periodo 2017 a 2020 .

- En el ámbito del empleo público, a través de acciones positivas como la reserva en las ofertas de empleo público de un cupo de plazas no inferior al 7\% para personas con discapacidad, celebrándose procesos selectivos independientes para el $2 \%$ de

\footnotetext{
99 Según la encuesta recientemente realizada a una muestra de 400 empresas privadas, no agrarias de cincuenta y más personas empleadas que están obligadas a contratar a PCD en un número equivalente al $2 \%$ de sus plantillas. Una cuota que incumple el 42,5\% de las empresas. Vid. SCUDIERI, Laura., Guaglianone, Luciana, Escudero, Ricardo, y Crespo Puras, Carmen, "Inclusión socio-laboral...”, op. cit., p. 58 y 59.

${ }^{100}$ Cfr. Moratalla Santamaría, Pablo, “Centros Especiales de Empleo”, op. cit., p. 5 y ss.
} 
dichas plazas reservadas para PCD intelectual. Asimismo, se reservan anualmente al menos el 7\% de las plazas ofertadas de formación sanitaria especializada para ser cubiertas por personas con discapacidad.

- Impulso del diálogo civil mediante la participación de las asociaciones y entidades relacionadas con la discapacidad en el diseño, aplicación y seguimiento de las políticas públicas que afecten directa e indirectamente a la discapacidad, a través del Consejo Nacional de la Discapacidad y de otros órganos y procedimientos y de reuniones informales con las entidades, además de la continua coordinación y colaboración con las mismas.

- En el ámbito de la participación social, fortaleciendo la capacidad de interlocución del tercer sector de acción social ante la Administración del Estado.

- La sensibilización social a través de los Premios Reina Sofía de discapacidad, convocados anualmente, se ha visto reforzada con la creación del premio de Tecnologías de la Accesibilidad en el 2014 y del premio de Cultura Inclusiva en el 2015, cumpliendo con la Estrategia Integral de Cultura para Todos.

- En materia de accesibilidad, se ha aprobado el Real Decreto 1056/2014, de 12 de diciembre, por el que se regulan las condiciones básicas de emisión y uso de la tarjeta de estacionamiento para $\mathrm{PCD}^{101}$. Mediante esta norma se garantiza la seguridad jurídica de cualquier ciudadano con discapacidad con movilidad reducida y unas condiciones iguales de uso de la tarjeta de aparcamiento en todo el territorio nacional. También en este terreno de la accesibilidad, anualmente se realiza un informe sobre la aplicación de la "Estrategia Integral de Cultura para Todos. Accesibilidad a la cultura para las personas con discapacidad"102, en el que se recogen los avances en la aplicación de las medidas establecidas en la Estrategia.

- En noviembre de 2015 el Gobierno aprobó la "Estrategia Española en Trastornos del Espectro del Autismo" "103, marco de referencia en la definición de las políticas y acciones estatales en este ámbito. A través de 15 líneas estratégicas con objetivos definidos en campos como la educación, el empleo, la salud, la accesibilidad o la participación, entre otros, la Estrategia está orientada a constituir el soporte esencial para mejorar la inclusión social, la calidad de vida y la protección de los derechos de las personas con trastornos del espectro del autismo.

\footnotetext{
${ }^{101}$ BOE n⿳ $^{\text {o } 309, ~ d e ~} 23$ de diciembre de 2014.

${ }^{102} \mathrm{Cfr}$. https://www.mscbs.gob.es/ssi/discapacidad/docs/estrategia_cultura_para_todos.pdf.

${ }^{103}$ Cfr. https://www.mscbs.gob.es/ssi/discapacidad/informacion/estrategiaEspanolaAutismo.htm.
} 
- La Red Española de Información y Documentación sobre Discapacidad (en adelante, REDID) es el resultado de la colaboración de los servicios de documentación e información sobre discapacidad vinculados al Ministerio de Sanidad, Servicios Sociales e Igualdad. Está formada por el Centro Español de Documentación sobre Discapacidad (en adelante, CEDD), el Observatorio Estatal de la Discapacidad (en adelante, OED) y el Servicio de Información sobre Discapacidad (en adelante, SID). La REDID coordina la labor documental, informativa e investigadora de sus componentes en materia de discapacidad, mejorando y ampliando la oferta de información destinada a personas con discapacidad, a expertos y al resto de los ciudadanos, contribuyendo a la gestión del conocimiento en el ámbito de la discapacidad, facilitando el acceso a los datos, análisis e informaciones más relevantes e impulsando el intercambio de ideas y experiencias. Además de la labor de coordinación, la REDID ha promovido la publicación de la Revista Española de Discapacidad y la creación del Repositorio Iberoamericano de Discapacidad.

- La Oficina de Atención a la Discapacidad (en adelante, OADIS) dependiente de la Dirección General de Políticas de Apoyo a la Discapacidad trabaja en: la promoción de la igualdad de oportunidades, la no discriminación y la accesibilidad universal de las personas con discapacidad; información, sensibilización y trato con tareas formativas sobre el derecho a la igualdad de oportunidades, no discriminación y accesibilidad universal de las personas con discapacidad; apoyo y asesoramiento a personas con discapacidad que han sido objeto de discriminación en materias relacionadas con las telecomunicaciones y la sociedad de la información, los espacios públicos urbanizados, infraestructuras y edificación, relaciones con las administraciones públicas, los transporte, los bienes y servicios a disposición del público, la administración de justicia y el patrimonio cultural; y recomendaciones a los distintos ministerios para que tengan en cuenta el grado de cumplimiento sobre la no discriminación y la accesibilidad universal de las PCD.

Por estos motivos, son necesarias todavía muchas y continuadas decisiones políticas de generación de cambio en lo referido a discapacidad. Es en el debate político, social y jurídico sobre la discapacidad y su lugar en la sociedad donde se va a determinar, entre otros, el contenido, extensión y garantía de los derechos de las PCD. Hay que impulsar las políticas sobre discapacidad con un enfoque transversal y holístico como única estrategia para comenzar a borrar prejuicios y reconocer derechos como personas. El principio de "Transversalidad" debe entenderse no sólo en relación con las actuaciones diseñadas para mejorar y garantizar los derechos de las PCD, sino como un elemento esencial para que, incorporando a las PCD en la máxima medida y en todos los ámbitos de la realidad social, éstas coadyuven a la consecución de objetivos de carácter general y estratégico de toda la población y de todas las políticas. Relacionado con la 
transversalidad ha de entenderse la "Compatibilidad", haciéndose necesario acuñar el hecho de que cualquier actuación, física, de infraestructuras, presupuestaria o legislativa que se ejerce sobre los derechos de las PCD es plenamente compatible con el entorno del ecosistema social, político y administrativo ${ }^{104}$. Ello implica, además, la necesidad de promover un "Cambio cultural" integral en la sociedad y la incorporación de la componente de discapacidad desde los órganos de política social, para avanzar un escalón en la madurez cultural y administrativa de las Administraciones Públicas ${ }^{105}$.

\subsection{Plan Integral de Acción de Mujeres con Discapacidad 2013-2016}

El Comité Español de Representantes de Personas con Discapacidad (CERMI) ha elaborado a través de su Área de Género el II Plan Integral de Acción de Mujeres con Discapacidad 2013-2016 ${ }^{106}$, como herramienta estratégica para impulsar sistemáticamente las políticas públicas de género y discapacidad en los próximos tres años. La situación de discriminación y exclusión de las mujeres y niñas con discapacidad, así como la de las mujeres cuidadoras de PCD, sigue siendo en nuestro país un problema de primer orden que exige la adopción de medidas específicas que incidan sobre las causas reales que le dan origen. El trabajo desarrollado por el CERMI en este ámbito ha servido para mostrar cómo la confluencia de dos ejes de discriminación, como el género y la discapacidad, generan situaciones de violación de derechos humanos que han pasado totalmente inadvertidos y que merecen ser abordados de manera sistemática a partir de un nuevo enfoque, que permita poner el acento en aquellos ámbitos por donde las organizaciones de PCD y del movimiento de mujeres no se han detenido.

Un plan de estas características se enmarca en las denominadas "medidas de acción positivas", entendidas como estrategias que tienen un carácter limitado en el tiempo y que cuyo objetivo es contribuir a eliminar prejuicios, actitudes, discursos y prácticas que dificultan a un determinado grupo social alcanzar una situación real de igualdad de oportunidades; en este caso, las mujeres y niñas con discapacidad fundamentalmente, aunque no en exclusiva. Este II Plan viene a dar continuidad al trabajo ya iniciado en 2005 con el I Plan Integral de Acción del CERMI, introduciendo, por un lado, una serie de mejoras, que son fruto del aprendizaje de los últimos años, así como objetivos y medidas que dan continuidad a las que en su día fueron incluidas en el I Plan y acciones novedosas que tratan de dar respuesta a realidades no tenidas en cuenta anteriormente, $\mathrm{o}$ que no fueron consideradas prioritarias.

\footnotetext{
${ }^{104}$ Cfr. Plan de Acción de la Estrategia Española sobre Discapacidad 2014-2020, p. 60.

105 Ibídem, p. 60 y 61.

106 (https://www.cermi.es/es/colecciones/ii-plan-integral-de-acci\%C3\%B3n-de-mujeres-con-discapacidad2013-2016).
} 
Este sería el caso de la inclusión en este II Plan de las mujeres cuidadoras de PCD, cuya situación presenta características específicas que deben ser abordadas en este marco. Precisamente el Preámbulo de la CIDPCD señala al respecto la importancia de que las familias de las PCD reciban también protección y asistencia para que así puedan contribuir a que las personas con discapacidad gocen de sus derechos plenamente y en igualdad de condiciones. Aquí se inscribirían las mujeres cuidadoras del entorno familiar (prioritariamente madres, parejas, hijas y hermanas) que han sido contempladas en este II Plan con el fin de promocionar sus derechos para alcanzar la igualdad de oportunidades, sin prejuicio de que sean las mujeres y las niñas con discapacidad las protagonistas del grueso de objetivos y medidas propuestos en el mismo.

Para su elaboración se ha tomado como marco legal y ejecutivo de referencia fundamental dos tratados internacionales de derechos humanos, como son: la Convención sobre la Eliminación de todas las formas de discriminación contra la mujer, adoptada por Naciones Unidas en el año $1979^{107}$, y la ya mencionada supra CIDPCD, adoptada también por Naciones Unidas en 2006. Complementariamente, se han tenido presente otros documentos de relevancia, como por ejemplo la "Declaración del Milenio"108, adoptada por Naciones Unidas en el año 2000 y la "Estrategia Europea de Discapacidad 2010-2020: Un compromiso renovado para una Europa sin barreras" ${ }^{109}$.

\subsection{La Estrategia Española de la Discapacidad 2016-2020}

La última decisión del Gobierno de España, la Estrategia Española de la Discapacidad 2012-2020 ${ }^{110}$, es una muestra de ese proceso incesante de intensificación de las políticas públicas de discapacidad. La Estrategia tiene como propósito configurarse como el elemento troncal de una visión y una acción consolidadas e integrales a largo plazo, que sirva de referencia permanente y sea la hoja de ruta de las futuras políticas públicas en materia de discapacidad en España, así como de las demás políticas públicas que tengan incidencia en la esfera de las PCD. Para ello, se realiza un diagnóstico de la situación actual de las PCD, y se define un objetivo marco: coadyuvar al cumplimiento de los objetivos cuantificados relacionados con el mercado laboral, la educación, la pobreza y

\footnotetext{
107 Adoptada y abierta a la firma y ratificación, o adhesión, por la Asamblea General en su resolución 34/180, de 18 de diciembre de 1979. Entrada en vigor: 3 de septiembre de 1981, de conformidad con el artículo 27. BOE n ${ }^{\circ}$ 69, de 21 de marzo de 1984.

${ }^{108}$ Naciones Unidas, Asamblea General (A/RES/55/2), 13 de septiembre de 2000.

${ }^{109}$ COMISIÓN EUROPEA, Bruselas, 15.11.2010 COM (2010) 636 final.

${ }^{110}$ Aprobada el 14 de octubre de 2011 por el Consejo de Ministros a propuesta del Ministerio de Sanidad, Política Social e Igualdad. (https://sid.usal.es/idocs/F8/FDO26112/Estrategia2012_2020.pdf).
} 
la exclusión social previstos en la Estrategia Europea 2020 y en el Programa Nacional de Reformas de España $2011^{111}$.

Asimismo, se prevén objetivos clásicos e imprescindibles como la accesibilidad a los entornos, la mejora del conocimiento sobre la situación vital de las PCD, la participación, la igualdad de trato y la no discriminación. Estos objetivos predeterminan unas líneas de actuación o medidas estratégicas, que deben inspirar todas las políticas y acciones públicas que puedan incidir, aunque sea tangencialmente, en la esfera de derechos y en la situación de las PCD. Las medidas estratégicas de la Estrategia Española sobre Discapacidad 2012-2020 se articularán y concretarán en dos planes de acción, correspondientes a los periodos 2012-2015 y 2016-2020, y en su ejecución participarán todas las administraciones, por lo que será relevante la búsqueda del acuerdo respecto al contenido de dichos planes. Con todo, la Estrategia ha sido criticada por la doctrina al no incorporar medidas concretas de acción positiva, lo que hubiera favorecido la consecución de su objetivo principal ${ }^{112}$.

\section{El papel de la negociación colectiva en la inserción laboral de las mujeres discapacitadas}

No hay duda en cuanto a que, la negociación colectiva (NC, en delante), no sólo es, como se ha dicho, "un derecho fundamental y una herramienta poderosa para conseguir el éxito económico y la equidad social, sobre todo en tiempos de transformación profunda", sino que, a la vez, "contribuye a la adaptabilidad, la agilidad y la resiliencia de las empresas, los mercados laborales y las economías" ${ }^{113}$. De este modo, la NC, representa hoy el centro neurálgico de estrategias negociadas de adaptación y de transición ante los cambios en la futura gobernanza del trabajo, siendo innegable el papel protagonista que ha de desempeñar en el presente y en el futuro del trabajo. $\mathrm{Y}$ ello, especialmente, en un momento en el que la digitalización de la economía presenta múltiples implicaciones y efectos en las relaciones laborales, y en el que, un fenómeno tan complejo, no permite una enumeración cerrada de sus repercusiones ${ }^{114}$.

En este mare magnum de incertidumbres y certezas, la NC emerge, de un lado, como una herramienta determinante para promover la integración de las MCD en el empleo

\footnotetext{
${ }^{111}$ (https://www.lamoncloa.gob.es/consejodeministros/Paginas/enlaces/29042011ProgramaEstabilidadRef ormas.aspx).

112 PÉREZ PÉREZ, Jorge, "La cuota de reserva a favor de las personas con discapacidad: una visión crítica de la regulación de las medidas alternativas a su cumplimiento", Revista Doctrinal Aranzadi Social, vol. 5, $\mathrm{n}^{\mathrm{o}} 4,2012$, p. 135 a 137.

${ }^{113}$ Cfr.: Negociación colectiva: guía de políticas. Lima: OIT, 2016, p. 4 y ss.

114 ÁLVAREZ CUESTA, Henar, "El diálogo social y la negociación colectiva como herramientas para lograr una transición digital justa", Lan harremanak: Revista de relaciones laborales, nº 42, 2019, p. 16.
} 
$\operatorname{ordinario}^{115}$, a la zaga de su integración social plena; y, de otro, como un instrumento privilegiado para que, a través del mismo, organizaciones sindicales y empresariales tomen bajo su responsabilidad la resolución de problemas que atañen de forma directa a su ámbito exclusivo de actuación, es decir, a las relaciones laborales (en este caso del colectivo de personas discapacitadas), tanto en el nivel de empresas como en el nivel superior a las mismas, o sea, los sectores en cada nivel (provincial, Comunidad Autónoma, Estatal).

Precisamente, a raíz de los últimos Acuerdos Interprofesionales a nivel estatal (III y IV Acuerdo para el empleo y la negociación colectiva, AENC), la negociación colectiva ha de abordar las cuestiones relacionadas con la integración laboral de las PCD en el empleo ordinario. El III AENC 2015-2017 ${ }^{116}$, prorrogado por el IV AENC 2018-2020117 en materia de protección de PCD, encomienda a los convenios colectivos tener en cuenta, de una parte, las características de los sectores y las empresas, las capacidades y aptitudes de los trabajadores y la posible adaptación de los puestos de trabajo a efectos de favorecer la incorporación al empleo ordinario de los trabajadores con discapacidad; y, de otra, la discapacidad de que se trate en relación con los necesarios ajustes razonables que se deban realizar en la adaptación de los puestos de trabajo.

Sin embargo, nos evidencia que realmente aporta pocas novedades respecto de las previsiones normativas sobre el empleo ordinario de las PCD, limitándose bien a realizar declaraciones de intenciones de los firmantes o a reiterar lo previsto en la normativa sobre el empleo ordinario de las $\mathrm{PCD}^{118}$. Asimismo, el III AENC establece que mediante la NC se favorecerá la incorporación al empleo de los trabajadores con discapacidad, atendiendo a determinados factores. Por lo que nos hallamos ante una mera una declaración de intenciones, dado que no aporta ningún valor añadido, ya que las PCD tienen, como el resto de personas, derecho al trabajo ${ }^{119}$.

Por su parte, el IV AENC, cuyo ámbito territorial es estatal, realmente no ha establecido nada nuevo respecto de la integración laboral de las PCD en empresas del mercado ordinario de trabajo, en las que el porcentaje mayoritario de trabajadores está compuesto por personas sin discapacidad. Ello se debe a que verdaderamente no estamos ante un

\footnotetext{
${ }^{115}$ RIBEs MoREnO, María Isabel, "Cabe utilizar la negociación colectiva...”, op. cit., p. 366.

${ }^{116} \mathrm{BOE} \mathrm{n}^{\mathrm{o}} 147$, de 20 de junio de 2015.

${ }^{117}$ BOE n $^{\text {o }} 173$, de 18 de julio de 2018.

118 BARBANCHO TOVILlAS, Fernando, RoMEO, Marina, y YePES-BALdÓ, Monserrat, "IV AENC e integración laboral de las personas con discapacidad ¿nuevo impulso para la negociación colectiva?”, Lan harremanak: Revista de relaciones laborales, $\mathrm{n}^{\mathrm{o}}$ 42, 2019, p. 1-20.

119 Barbancho Tovillas, Fernando, Romeo, Marina, y YePeS-BAldó, Monserrat, "IV AENC e integración laboral de las personas con discapacidad...”, op. cit., p. 10.
} 
nuevo acuerdo interconfederal, sino ante una especie de adenda, que se añade al precedente $^{120}$.

De modo que, en cómputo global, el tratamiento relativo a la inserción laboral de los trabajadores discapacitados en los convenios colectivos es escaso, disperso, poco sistemático y en la mayoría de los casos, con nulo compromiso contractual ${ }^{121}$. De hecho, los convenios colectivos que han tratado la cuestión suponen un número relativamente reducido tanto en la $\mathrm{NC}$ sectorial como en la de empresa. Esto pone de manifiesto una primera limitación cuantitativa; de esta limitación se deriva como consecuencia inmediata la escasa utilización y por lo tanto el papel insuficiente que en esta cuestión viene jugando la NC y las parcas posibilidades de que, en estas condiciones, pueda lograr una incidencia importante sobre el problema del empleo de las $\mathrm{PCD}^{122}$. Pero también evidencia una limitación cualitativa; el análisis de la NC sectorial y empresarial señala una escasa voluntad de inserción de cláusulas que vayan dirigidas a este colectivo, de hecho, solo esporádicamente figuran algunas que revelen el compromiso con el empleo de las PCD, incluso cuestiones como pueden ser la necesidad de realizar los ajustes razonables para los puestos ocupados por discapacitados tienen escasa implantación ${ }^{123}$. Todo ello da lugar, aparte de a una frugal profundidad de los contenidos, a una realidad atomizada, carente de estructuración y de sistematicidad en su tratamiento. Las cláusulas así pactadas agotan rápidamente su recorrido aplicativo y no dan oportunidad apenas a realizar nuevos planteamientos en ulteriores negociaciones del convenio ${ }^{124}$.

Abordar las posibles causas a las que responde este fenómeno, requeriría un análisis monográfico que excede de nuestro propósito. Pero, no cabe duda que, en una primera aproximación al problema, se vislumbran claramente dos causas sobre las que poder sustentarlo. Una, vinculada con cómo la disrupción sistémica y global que representan las nuevas tecnologías, y que amenazan con desregular completamente el mercado de trabajo tal como lo conocemos hoy en día, supone un plus de complejidad que retrae seriamente a las partes negociadoras, especialmente, tratándose de trabajadores discapacitados. Y otra, la profunda crisis de los sindicatos sostenida en el tiempo. Las organizaciones sindicales, en cuya acción ha venido descansando en gran medida el derecho del trabajo,

\footnotetext{
${ }^{120}$ FERNÁNDEZ AVILÉS, Jose Antonio, “El diálogo social se mueve: ¿qué novedades nos trae el IV Acuerdo para el Empleo y la Negociación Colectiva?”, Revista de Trabajo y Seguridad Social, Comentarios y casos prácticos, $\mathrm{n}^{\circ}$ 428, 2018, p. 7.

121 SCUdieri, Laura, GuAglianone, Luciana, Escudero, Ricardo, CresPo PURAS, Carmen, Inclusión socio-laboral..., op. cit., p. 58.

${ }^{122}$ Vid. Guía para favorecer el empleo de las personas con discapacidad a través de la negociación colectiva, 2014, Fundación F. Largo caballero, p. 39. (http://portal.ugt.org/fflc/estudios/guia5_1.pdf).

${ }^{123}$ RiBes Moreno, María Isabel, “Cabe utilizar la negociación colectiva...”, op. cit., p. 386.

${ }^{124}$ Vid. Guía para favorecer el empleo de las personas con discapacidad..., op. cit., p. 39.
} 
encuentran nuevas y serias dificultades para su funcionamiento ${ }^{125}$; reforzarla es irrenunciable si pretendemos una transición justa a la digitalización ${ }^{126}$, que favorezca una transformación inclusiva en términos de empleo y condiciones de trabajo, y contribuya a prevenir y mitigar los riesgos de segmentación y exclusión social ${ }^{127}$.

Por tanto, quizá, un paso normativo necesario en la resolución del problema de inserción laboral de las MCD, sería el de integrar estos contenidos a través de la negociación colectiva, estableciendo dichas menciones como una propuesta de contenido mínimo en los convenios, de forma similar a la puesta en práctica para contribuir a la reducción de la desigualdad por género en el ámbito laboral de acuerdo a la Ley Orgánica 3/2007 128 .

A mayor abundamiento, y sobre la situación descrita ya de por sí preocupante, se alza otra casi más destacada. Se trata de la grave incoherencia normativa que existe con relación a la discapacidad sobrevenida y su tratamiento legislativo, en tanto que supone, en la mayoría de los casos, una ruptura con el mundo laboral ${ }^{129}$. Recordemos que, mientras las leyes invitan a realizar adaptaciones necesarias de los puestos de trabajo a las PCD, el Estatuto de los Trabajadores (ET), ex artículo 49, facilita la expulsión de los mismos del mercado de trabajo en caso de incapacidad sobrevenida. Así, la consecuencia de una declaración de Incapacidad Permanente (IP) Total, Absoluta o Gran Invalidez implica la extinción no indemnizada de la relación laboral, con dos salvedades:

- Que, a juicio del órgano de calificación, la incapacidad del trabajador pueda ser objeto de revisión por mejoría. En ese caso el contrato no se extingue, sino que queda suspendido por un periodo de dos años. Si en ese tiempo el trabajador mejora tiene derecho a su puesto de trabajo (artículo 48.2 ET).

\footnotetext{
${ }^{125}$ Goerlich PeSET, José María, "Revolución tecnológica y futuro del empleo. Reflexiones de un jurista del trabajo", Comisión Episcopal de Pastoral Social. La técnica al servicio del desarrollo humano integral. XXIV Curso de formación en Doctrina Social de la Iglesia Mesa redonda Madrid, 12 septiembre, 2017, p. 1-5. (http://www.instituto-social-leonxiii.org).

${ }^{126}$ Así se pone de manifiesto en el informe de la OIT: Trabajar para un futuro más prometedor: una primavera de esperanza para los trabajadores, en el que se reconoce que los sindicatos tienen un papel clave que desempeñar y que son colaboradores esenciales para la creación de un nuevo contrato social.

${ }^{127}$ Sobre los retos que plantea la digitalización para la acción sindical, véase RODRÍGUEZ FERNÁNDEZ, María Luz, "Sindicalismo y negociación colectiva 4.0", Temas Laborales, no 144, 2018, p. 31 y ss.

${ }^{128}$ RiBes MoRenO, María Isabel, "Cabe utilizar la negociación colectiva...”, op. cit., p. 366.

${ }^{129}$ Apenas 236.000 personas están en situación activa en España, de un total de 989.000 en edad de trabajar, lo cual arroja una tasa de actividad del $31,1 \%$ (dos puntos por debajo en las mujeres). Otros datos indican que apenas un $0,2 \%$ de la población regresa de manera inmediata al mercado de trabajo y que, casi la mitad, queda en situación inactiva percibiendo una prestación. Para más de 700.000 personas el período de permanencia sin trabajar es superior a 5 años.
} 
- El segundo caso, es cuando el convenio colectivo de aplicación recoja el derecho del trabajador en IP Total a ocupar un puesto de trabajo en la empresa compatible con su estado. Si ese puesto de trabajo conlleva una retribución menor, se compensa con la pensión que se percibe.

Es cierto que, desde la vertiente económica, el trabajador queda protegido con la prestación correspondiente en estos supuestos de invalidez, pero el trabajo, y no puede olvidarse esto, tiene otra dimensión de realización personal y dignificación del individuo $^{130}$, que debe ampararse igualmente. Por eso, es tan determinante que en la NC se incluya una cláusula de este tipo (presente, por cierto, en varios convenios colectivos, sobre todo de grandes empresas), estableciendo criterios de permanencia, tanto para las empresas privadas como para la Administración y los servicios públicos. Se trata de adaptar los puestos de trabajo, cualificar a la persona trabajadora en función de su nueva capacidad y garantizar que, en ninguno de los casos, suponga una merma de sus condiciones laborales. Desde aquí, instamos al legislador a una revisión y a un cambio de la actual ordenación para proteger de forma amplia a todas las PCD en el ámbito laboral y social, y corregir esta grave incoherencia normativa.

\section{Balance final y propuestas de lege ferenda}

1. Tal como hemos descrito supra, las MCD representan un colectivo con especiales dificultades de integración laboral. El primero de los retos al que nos enfrentamos pues, y muestra primera propuesta de lege ferenda, es la de promover una mayor penetración de este colectivo en el empleo ordinario, dado que el $71 \%$ de los contratos siguen firmándose en el ámbito protegido de los Centros Especiales de Empleo. Ciertamente, cumplen una importantísima misión social, pero muchas veces se olvida el carácter transitorio que marca la ley y el hecho de que la empresa ordinaria representa el máximo exponente de inclusión sociolaboral. Las políticas públicas tienen que generar oportunidades de empleo para las personas en situación de mayor vulnerabilidad, diseñando itinerarios personalizados de inserción para personas en riesgo o en situación de exclusión social como ocurre con las MCD. En este sentido, hay que incorporar una perspectiva transversal de género y discapacidad en las distintas actuaciones que se llevan a cabo por parte de la Administración Pública, e implantar políticas públicas de empleo que tengan presente el género y la discapacidad $\mathrm{y}$, por tanto, la situación específica de estas trabajadoras, así como su discriminación múltiple a consecuencia de la interseccionalidad de otros factores discriminantes, como edad, orientación sexual, minorías étnicas, ser víctima de violencia de género, estar en riesgo de pobreza, etc.

\footnotetext{
${ }^{130}$ Para un estudio en profundidad sobre el valor diverso del trabajo, vid. CERDÁ FIOL, Antonia, Las dimensiones sociales del trabajo en la actualidad, Universitat de les Illes Balears, 2017.
} 
Estas medidas, han de ir complementadas con aquellas otras dirigidas a recibir apoyo y asistencia, así como con la implementación de intervenciones institucionales y legales para evitar la discriminación y la exclusión social en un tratamiento holístico y transversal del problema. Ello implicaría la transformación de hábitos, actitudes y comportamientos, fomento del empleo como factor clave para la inserción social, aseguramiento de la salud, aseguramiento frente a riesgos profesionales, sistema general de pensiones, apoyo especial a mujeres y menores con discapacidad, apoyo a las familias, servicios que promuevan la vida independiente, servicios de rehabilitación, barreras y prácticas institucionales, sector cultural, comunicaciones, etc. Y, además, ayudaría a promover un necesario "Cambio cultural" integral y de mentalidad en la sociedad y la incorporación de la componente de discapacidad desde los órganos de política social, para avanzar un escalón en la madurez cultural y administrativa de las Administraciones Públicas.

2. Asimismo, existe una clara necesidad de fomentar políticas de promoción de la autonomía personal y de atención a las personas en situación de dependencia, que, en el marco de una política de cuidados (concebida desde un enfoque de derechos humanos), tome en consideración la realidad de las MCD, no solamente como receptoras de cuidado, sino también como proveedoras del mismo, circunstancia ésta, que suele ignorarse de manera sistemática. Con este objetivo proponemos, de lege ferenda, introducir la discapacidad como supuesto del artículo $34.8 \mathrm{ET}$, dado que no lo contempla como excepción y, en esa medida, las necesidades adicionales de las familias que tienen PCD no quedan cubiertas. Se propone, pues, promover un marco legal que amplíe esta normativa garantizando fórmulas como la utilización de la jomada continua, el horario flexible u otros modos de organización del tiempo de trabajo y descansos que faciliten la compatibilidad de la conciliación de la vida personal y profesional de las MCD o de los trabajadores que conviven con ellas.

3. Aunque la Negociación Colectiva (NC) emerge como una herramienta determinante para promover la integración de las MCD en el empleo ordinario, el análisis de la negociación sectorial y empresarial española demuestra que, en cómputo global, el tratamiento relativo a la inserción laboral de los trabajadores discapacitados en los convenios colectivos es escaso, disperso, poco sistemático y en la mayoría de los casos, con nulo compromiso contractual. De hecho, los convenios colectivos que han tratado la cuestión, aparte de ser un número relativamente reducido, tanto en el ámbito sectorial como en el de empresa, destacan por una escasa voluntad de inserción de cláusulas que vayan dirigidas a este colectivo; es más, solo esporádicamente figuran algunas que revelen el compromiso, casi siempre muy limitado, con el empleo de las PCD, e incluso cuestiones como pueden ser la necesidad de realizar los ajustes razonables para los puestos ocupados por discapacitados tienen poca o nula implantación. Por tanto, quizá, un paso normativo necesario en la resolución del problema de inserción laboral de las 
MCD, y ahí radica nuestra tercera propuesta de lege ferenda, sería el de integrar estos contenidos a través de la negociación colectiva, estableciendo dichas menciones como una propuesta de contenido mínimo en los convenios, de forma similar a la puesta en práctica para contribuir a la reducción de la desigualdad por género en el ámbito laboral de acuerdo a la Ley Orgánica 3/2007.

Además, se propone una rectificación normativa del artículo 49 ET en tanto que supone, en la mayoría de los casos, una ruptura con el mundo laboral. Recordemos que, mientras las leyes invitan a realizar adaptaciones necesarias de los puestos de trabajo a las MCD, el ET, ex artículo 49, facilita la expulsión de los mismos del mercado de trabajo en caso de incapacidad sobrevenida es tan determinante que en la NC se incluya una cláusula de este tipo, estableciendo criterios de permanencia, tanto para las empresas privadas como para la Administración y los servicios públicos. Se trata de adaptar los puestos de trabajo, cualificar a la persona trabajadora en función de su nueva capacidad y garantizar que, en ninguno de los casos, suponga una merma de sus condiciones laborales.

4. Constatada, por último, la importancia que tiene la formación en la inclusión sociolaboral de colectivos vulnerables, es necesario aplicar políticas dirigidas a fomentar la enseñanza universitaria entre las PCD, dado que tendrán un efecto determinante sobre su incorporación al mercado laboral mediante contratos de trabajo estables. En la sociedad del conocimiento la exclusión está ligada cada vez más a los niveles educativos. Desde esta perspectiva, entendemos que es absolutamente preciso revisar los itinerarios y las barreras que existen en las etapas educativas anteriores para favorecer la inclusión de las PCD. Por ello, nuestra cuarta propuesta de lege ferenda está orientada a la necesidad de impulsar políticas de activación sociolaboral de las MCD que incidan en la formación, como fase previa para alcanzar la plena participación en el empleo, especialmente las MCD intelectual o del desarrollo, así como las mujeres del entorno rural y con pluridiscapacidades, articulándose los apoyos en el empleo que, en cada caso, sean necesarios.

En este marco, hay que impedir que estas trabajadoras se queden atrás en el proceso de transformación digital que también afecta, y de manera plena, al mercado laboral. No solo como medida de inserción laboral, sino como forma de evitar la segregación horizontal y vertical a las que se ven sometidas.

Para empezar, proponemos fomentar un ecosistema nacional para el desarrollo y el reconocimiento del talento habilitador de la transformación digital en España con el fin de promover, educar y formar en las nuevas competencias digitales que demandan las organizaciones del sector TIC y otros sectores que están en el proceso de digitalización. $\mathrm{Y}$, asimismo, proponemos identificar todos los posibles riesgos de exclusión digital y 
actuar tanto con medios públicos como privados, para evitar cualquier brecha y favorecer la inclusión digital de las PCD, especialmente, sabiendo que existe y persiste una generalizada infrarrepresentación de las mujeres en sector TIC y también entre las profesiones con especialización en dichas tecnologías. Pero, además, como medidas complementarias a las políticas públicas que gestionen en este ámbito, proponemos, de un lado, la creación de un observatorio de brecha digital con participación de todos los sectores implicados, incluidas, especialmente, las asociaciones de personas con diversidad funcional, que elabore los indicadores de referencia para la medición de los diferentes tipos de brecha y establezca los objetivos a lograr anualmente para la eliminación de barreras. Y, de otro, diseñar un catálogo de cursos de formación digital para ayudar a colectivos especialmente vulnerables como las MCD.

\section{Bibliografía}

Alija Fernández, Rosa Ana., "La transversalidad de los Derechos Humanos en las políticas públicas y su eficacia en períodos de crisis", en VVAA: El derecho internacional de los derechos humanos en períodos de crisis: estudios desde la perspectiva de su aplicabilidad, BONET I PÉREZ, Jaume y SAURA EstAPÀ. Jaume (Coords.), 2013, p. 31-52.

Álvarez Cuesta, Henar, "El diálogo social y la negociación colectiva como herramientas para lograr una transición digital justa", Lan Harremanak: Revista de relaciones laborales, 2019, n ${ }^{\circ} 42$ (dedicado a: Digitalización, conciliación y trabajo como mercancía), p. 13-49.

Avaria SAAVEDRA, Andrea, “Discapacidad: exclusión/inclusión”, Revista de la maestría de antropología y desarrollo, $\mathrm{n}^{\circ}$ 5, 2001, p. 10 y 11.

BALlester CARDell, María, "Mujer y discapacidad", en VVAA, La discriminación múltiple en los ordenamientos jurídicos español y europeo, Rosario SERRA (Dir.), Valencia, tirant lo blanch, 2013.

Barbancho Tovillas, Fernando, Romeo, Marina, YePes-BAldó, Monserrat, "IV AENC e integración laboral de las personas con discapacidad ¿nuevo impulso para la negociación colectiva?", Lan Harremanak: revista de relaciones laborales, nº 42, 2019 (ejemplar dedicado a: digitalización, conciliación y trabajo como mercancía), p. 1-20.

BECK, Ulrich, "Risk society”, SAGE publications, London, 1942. 
BOARDMAN, Jed, GROVE, Bob, PERKINS, Rachel y SHEPHERD, Geoff, "Work and employment for people with psychiatric disabilities". the British journal of psychiatry, 182 (6), 2003, p. 467-468.

CARIACEDO PÉREZ, Lola, "Mujeres jóvenes y nuevas tecnologías. Nuevas actrices y herramientas para una vieja deuda", en AGUINAGA, Josune (coord.), Revista de Estudios de Juventud, ${ }^{\circ}$ 83, mujeres jóvenes en el siglo XXI, INJUvE. Madrid. 2008.

CARRIZOSA PRIETO, Esther, "Lifelong learning e industria 4.0. elementos y requisitos para optimizar el aprendizaje en red", Revista Internacional y Comparada de Relaciones Laborales y Derecho, $\mathrm{n}^{\circ}$ 1, vol. 6, 2018, p. 38-63.

CAzallas AlCAIDE, Carlos, "La segregación ocupacional de las personas con discapacidad en españa", Anales de Economía Aplicada, 2007, MoYAno PESQUERA, Pedro (coord.), Somarriba Arechavala, Noelia; Fernández Arufe, Josefa (dir.), y Rojo García, José luis (dir.), vol. 9, 2007, p. 50-68.

CERDÁ FIOL, Antonia, "Las dimensiones sociales del trabajo en la actualidad", Universitat de les Illes Balears, 2017.

Cordero Martín, Guadalupe, Garrido Reina, Paloma, "Intervenir en el techo de cristal desde prácticas innovadoras", Revista Educativa Hekademos, nº 18, 2015, p. 7-14.

DÁvila Quintana, Carmen Delia, Malo OcañA, Miguel Ángel, "Género, discapacidad y posición familiar: la participación laboral de las mujeres con discapacidad", Cuadernos Aragoneses de Economía, no 16 (1), 2006.

FERNÁNDEZ AviLÉS, José Antonio, "El diálogo social se mueve: ¿qué novedades nos trae el iv acuerdo para el empleo y la negociación colectiva?", Revista de Trabajo y Seguridad Social, comentarios y casos prácticos, $\mathrm{n}^{\circ} 428,2018$, p. 7-16.

FERNÁNDEZ ORRICO, Francisco Javier, "Cuotas de reserva y ajustes razonables para trabajadores con discapacidad en el ámbito laboral ordinario", Revista Española de Derecho del Trabajo, nº 195/2017 parte estudios, editorial Aranzadi, Cizur menor. 2017.

GIL GARCÉS, Esteban, “Discapacidad, empleo y nuevas tecnologías”, Revista de Trabajo y Seguridad Social CEF, nº 204, 2000. 
Giménez LóPeZ, Dulce, Ramos LoRente, María del Mar, "La discriminación de las mujeres discapacitadas en España", Revista del Ministerio de Trabajo e Inmigración, $\mathrm{n}^{\mathrm{o}}$ 45, 2003, p. 61-76.

GoERLICH PeSET, José María, "Revolución tecnológica y futuro del empleo. reflexiones de un jurista del trabajo", Comisión Episcopal de Pastoral Social. La técnica al servicio del desarrollo humano integral, XXIV curso de formación en doctrina social de la iglesia mesa redonda Madrid, 12 septiembre, 2017, p. 1-5. (http://www.instituto-socialleonxiii.org)

Gomiz PASCUAL, María Pilar, "TIC y mujeres con discapacidad una ventana al mundo", Revista de Estudios de Juventud, $\mathrm{n}^{\circ}$ 111, 2016, p. 119-140

GONZÁlEZ RAMOS, Pilar, "Las mujeres con discapacidad y sus múltiples desigualdades; un colectivo todavía invisibilizado en los estados latinoamericanos y en las agencias de cooperación internacional", XIV Encuentro de Latinoamericanistas Españoles: Congreso Internacional, 2010, Santiago de Compostela, España, p. 2737-2756

InIESta MartíneZ, Almudena, MuÑoz SÁnCHEZ, Práxedes, "invisibilidad de la violencia de género en mujeres con diversidad funcional", International Journal of Developmental and Educational Psychology, vol. 4, n ${ }^{\circ}$ 1, 2017, p. 195-202.

Malo Ocaña, Miguel Ángel, Cueto Iglesias, Begoña, Rodríguez Álvarez, Vanesa, "Compatibilizando pensiones por discapacidad y empleo en España", Papeles de Economía Española, no 161, 2019, p. 55-70.

Martín Trillo, Patricia, "análisis crítico de las políticas públicas de empleo en la discapacidad y el género", Documentos de Trabajo Social: Revista de Trabajo y Acción Social, no 60, 2017, p. 139-170.

Martínez-Cantos, José Luis, Castaño Collado, Cecilia, "la brecha digital de género y la escasez de mujeres en las profesiones tic", Panorama Social, n 25, 2017, p. 49-65.

Mercado García, Esther, AizPurúa González, Eva, García Vicente, Luis Mariano, "Avanzando hacia la igualdad de oportunidades en la inclusión socio-laboral de las personas con discapacidad", Cuadernos de Trabajo Social, vol. 26-1, 2013, p. 95-104.

Moratalla Santamaría, Pablo, "Centros Especiales de Empleo", CIRIEC - España. Revista Jurídica de Economía Social y Cooperativa, no 29, 2016, p. 235-274 
Nieto Rojas, Patricia, "Políticas de protección a los menores con discapacidad, dependientes o enfermos crónicos. en especial, su recepción por la seguridad social y el sistema para la autonomía y atención a la dependencia”, Revista Española de Derecho del Trabajo, n 217/2019 parte estudios, editorial Aranzadi, 2019.

PAgÁN Rodriguez, Ricardo, "Transtions to part-time work at older ages: the case of people with disabilities in europe", Disability\&society, 27 (1), 2012, p. 95-115.

Palacios Rizzo, Agustina, El modelo social de discapacidad: orígenes, caracterización y plasmación en la convención internacional sobre los derechos de las personas con discapacidad, Madrid, cinca, 2008.

PÉREZ PÉREZ, Jorge, "La cuota de reserva a favor de las personas con discapacidad: una visión crítica de la regulación de las medidas alternativas a su cumplimiento", Revista Doctrinal Aranzadi social, vol. 5, n 4, 2012, p. 135-166.

RIBES MoRENO, María Isabel, "Cabe utilizar la negociación colectiva para integrar laboralmente a las personas con discapacidad. una propuesta a la luz de la experiencia francesa", Lan Harremanak, vol. 35, 2/2016, p. 357-388.

RIVAS VALLEJO, Pilar, "Derechos fundamentales y prevención de riesgos laborales a la luz de la ley general de los derechos de las personas con discapacidad". vvaa: los derechos fundamentales inespecíficos en la relación laboral y en materia de protección social, XXIV Congreso Nacional de Derecho del Trabajo y de la Seguridad Social, Pamplona, mayo de 2014, Asociación Española de Derecho del Trabajo y de la Seguridad Social.

Rodríguez Álvarez, Vanesa, Cueto IGlesias, Begoña, "El trabajo de las personas con discapacidad ante la crisis", Revista Internacional de Organizaciones, nº 11, 2013.

RODRÍGUEZ FERNÁNDEZ, María Luz, "Sindicalismo y negociación colectiva 4.0”, Temas Laborales, $\mathrm{n}^{\circ} 144,2018$, p. 27-42.

Ruiz Castillo, María del Mar, Igualdad y no discriminación. la proyección sobre el tratamiento laboral de la discapacidad, ed. Bomarzo, 2010.

Ruiz SANTAMARÍA, José Luís, Vacios e insuficiencias en la adaptación y protección adecuada a las personas trabajadoras con discapacidad, Madrid, Aranzadi, 2019. 
Scudieri, Laura, Guaglianone, Luciana, Escudero, Ricardo, Crespo Puras, Carmen, “inclusión socio-laboral de las mujeres con discapacidad”, Madrid, España, 2019. (no publicado).

TORRES GONZÁlEZ, Arancha, "Inclusión digital, un plan de acción para combatir el analfabetismo y la exclusión digital", Capital Humano: Revista para la integración y desarrollo de los recursos humanos, $\mathrm{n}^{\mathrm{o}}$ 348, 2019.

VERGARA HEIDKE, Adrián, "El discurso sobre la discapacidad: principales dimensiones dicotómicas", Revista Latinoamericana de Estudios del Discurso, vol. 19, 2019, p. 94110. (vid: https://revistamad.uchile.cl/index.php/RMAD/article/view/14826). 